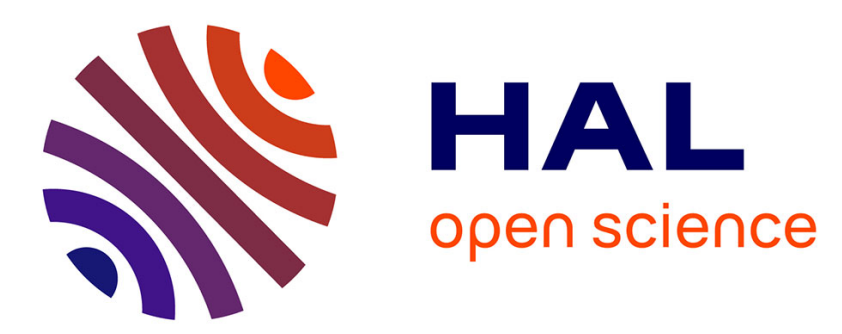

\title{
Is Rock-Eval 6 thermal analysis a good indicator of soil organic carbon lability? - A method-comparison study in forest soils
}

Laure Soucémarianadin, Lauric Cécillon, Claire Chenu, François Baudin, Manuel Nicolas, Cyril Girardin, Pierre Barré

\section{To cite this version:}

Laure Soucémarianadin, Lauric Cécillon, Claire Chenu, François Baudin, Manuel Nicolas, et al.. Is Rock-Eval 6 thermal analysis a good indicator of soil organic carbon lability? - A method-comparison study in forest soils. Soil Biology and Biochemistry, 2018, 117, pp.108-116. 10.1016/j.soilbio.2017.10.025 . hal-01654067

\section{HAL Id: hal-01654067 https://hal.science/hal-01654067}

Submitted on 13 Dec 2017

HAL is a multi-disciplinary open access archive for the deposit and dissemination of scientific research documents, whether they are published or not. The documents may come from teaching and research institutions in France or abroad, or from public or private research centers.
L'archive ouverte pluridisciplinaire HAL, est destinée au dépôt et à la diffusion de documents scientifiques de niveau recherche, publiés ou non, émanant des établissements d'enseignement et de recherche français ou étrangers, des laboratoires publics ou privés. 
Biology and Biochemistry

Manuscript Number: SBB12198R2

Title: Is Rock-Eval 6 thermal analysis a good indicator of soil organic carbon lability? - A method-comparison study in forest soils

Article Type: Research Paper

Keywords: soil organic carbon kinetic pools; Rock-Eval 6; particulate organic matter; soil basal respiration; deep soil organic carbon; French forest soils

Corresponding Author: Dr. Laure Nalini Soucemarianadin, Ph.D.

Corresponding Author's Institution: Ecole Nationale Supérieure

First Author: Laure Nalini Soucemarianadin, Ph.D.

Order of Authors: Laure Nalini Soucemarianadin, Ph.D.; Lauric Cécillon, PhD; Claire Chenu, PhD; François Baudin, PhD; Manuel Nicolas, PhD; Cyril Girardin, PhD; Pierre Barré, PhD

Manuscript Region of Origin: FRANCE 
1 Is Rock-Eval 6 thermal analysis a good indicator of soil organic carbon lability? - A method-

2 comparison study in forest soils

3

4 Laure Soucémarianadin ${ }^{\mathrm{a}, *}$, Lauric Cécillon ${ }^{\mathrm{b}}$, Claire Chenu $^{\mathrm{c}}$, François Baudin ${ }^{\mathrm{d}}$, Manuel

5 Nicolas $^{\mathrm{e}}$, Cyril Girardin ${ }^{\mathrm{c}}$ and Pierre Barré

6

$7 \quad{ }^{a}$ Laboratoire de Géologie, PSL Research University, CNRS-ENS UMR 8538, Ecole Normale 8 Supérieure, 24 rue Lhomond 75231 Paris CEDEX 5, France

9 b Université Grenoble Alpes, IRSTEA, 2 rue de la Papeterie, 38402 St-Martin-d'Hères, France

$10{ }^{\mathrm{c}}$ AgroParisTech-INRA, UMR ECOSYS, Route de la ferme, 78850 Thiverval-Grignon,

11 France

$12{ }^{\mathrm{d}}$ Sorbonne-Université/UPMC, ISTeP, 4 place Jussieu 75005 Paris, France

$13{ }^{\mathrm{e}}$ Office National des Forêts, R\&D, 77300 Fontainebleau, France

14

$15 *$ corresponding author: Laure Soucémarianadin, souce@geologie.ens.fr

16 


\section{Abstract}

Soil respiration tests and abundance of particulate organic matter (POM) are considered as classical indicators of the labile soil organic carbon (SOC) pool. However, there is still no widely accepted standard method to assess SOC lability and the pertinence of these two timeconsuming methods to characterize SOC turnover can be questioned. Alternate ways of determining the labile SOC fraction are thus much needed. Thermal analyses, in particular Rock-Eval 6 (RE6) analysis has shown promising results in the determination of SOC biogeochemical stability.

Using a large set of samples $(n=99)$ of French forest soils representing contrasted pedoclimatic conditions, including deep samples (up to $0.8 \mathrm{~m}$ depth), we compared three different methods used for SOC lability assessment. We explored whether respired-C isolated by a 10 -week laboratory soil respiration test, POM-C isolated by a physical SOC fractionation scheme (particle-size $>50 \mu \mathrm{m}$ and $\mathrm{d}<1.6 \mathrm{~g} \cdot \mathrm{cm}^{-3}$ ) and several RE6 parameters were comparable and how they correlated.

As expected, respired-C (mg CO $\left.2-\mathrm{C} \cdot \mathrm{g}^{-1} \mathrm{SOC}\right)$ and POM-C (\% of total SOC) fractions strongly decreased with depth. RE6 parameters showed that SOC from deeper soil layers was also thermally less labile, more oxidized and H-depleted. Indeed, SOC from deeper soil layers had lower proportion of thermally labile SOC, higher $\mathrm{T}_{50 \_ \text {HC_PYR }}$ (temperature at which 50\% of the pyrolysable hydrocarbons were effectively pyrolyzed) and $\mathrm{T}_{50 \_} \mathrm{CO}_{2} \mathrm{Ox}$ (temperature at which $50 \%$ of the $\mathrm{CO}_{2}$ gas had evolved during the oxidation phase), larger oxygen index, and smaller hydrogen index. Surprisingly, the two classical indicators of the labile SOC pool (respired-C and POM-C) were only marginally correlated $(p=0.051)$ and showed layerspecific correlations. Similarly, respired-C was poorly correlated to RE6 parameters. Conversely, the POM-C fraction showed a strong negative correlation with $\mathrm{T}_{50} \mathrm{HC}_{-} \mathrm{PYR}(\rho=$ -0.73 ) and good correlations with other RE6 parameters. 
43 Our study showed that RE6 parameters were good estimates of the POM-C fraction, which

44 represents a labile SOC pool with a residence time of $c a$. a couple decades that is meaningful 45 regarding SOC stock changes upon modifications in land management. RE6 thermal analysis 46 could therefore be a fast and cost-effective alternative to more time-consuming methods used 47 in SOC pool determination, and may be integrated into soil monitoring networks to provide 48 high-throughput information on SOC dynamics.

49

50 Keywords: soil organic carbon kinetic pools; Rock-Eval 6; particulate organic matter; soil 51 basal respiration; deep soil organic carbon; French forest soils; 


\section{Introduction}

Soil organic matter (SOM) degradation has multiple consequences on major soil functions

like nutrients cycling, soil emissions of greenhouse gases and affects soil carbon sequestration potential. In particular, the labile part of SOM (turnover $<20$ years) is associated with biological (microbial) activity and nutrient cycling (Haynes, 2005) and is very relevant to these issues.

In that context, information on the temporal trajectories of SOC storage at a fine spatial resolution, in the form of detailed mapping of SOC stock evolutions with time for different land management scenarios, are required. SOC dynamics models are the logical candidates to provide such information, but their predictive performance is not yet satisfying, and they would benefit from an improved initialization using fine-scale information on SOC kinetic pools (Luo et al., 2016). Soil monitoring networks have become more prominent in the last twenty years. However, currently they can only provide information relative to the recent temporal (decadal) evolution of total SOC stocks. To use the full potential of these networks and measure the effects of climate and land-use changes on SOC stocks will require indicators of the size of the different SOC pools.

Respiration measurements and particulate organic matter (POM) quantification obtained by various methods of fractionation (particle size only / density only / density + particle-size) (von Lützow et al., 2007) have been used for decades and are now classical estimates of the labile SOC pool.

Laboratory incubations are run under optimum temperature and moisture conditions and use the indigenous microflora. They thus represent a maximum potential rate of $\mathrm{C}$ mineralization and an index of $\mathrm{C}$ availability in the system, integrating the physical, chemical, and microbiological properties of the soil (Haynes, 2005). Incubations are fairly simple to set-up 
but they require space and are time-consuming. Sieving and rewetting also tend to artificially increase the mineralizable pool (Haynes, 1986).

Physical fractionation schemes are easy to implement and do not require expensive equipment although they can become costly when density fractionation is involved. Moreover they are very time-consuming, often requiring multiple and relatively long periods of agitation/settling and drying. The most important limitation is the ability of the fractionation scheme to isolate physical fractions that have homogeneous turnover and thus represent functional noncomposite SOC pools (von Lützow et al., 2007).

While respired-C and POM-C fractions both represent a labile SOC pool, the former corresponds to a smaller SOC pool with a shorter mean residence time (usually $<1$ year for temperate in-situ conditions) (Feng et al., 2016) while the latter corresponds to a larger SOC pool with a longer mean residence time (usually $<20$ year for temperate in-situ conditions) (e.g., Trumbore et al., 1996; Balesdent, 1996). Because these two methods are both very timeconsuming, they cannot address the needs of soil monitoring, i.e., a methodology that is informative, high-yield and relatively cheap to implement, to allow for the analysis of numerous samples.

Among thermal analyses used to characterize SOM, Rock-Eval 6 (RE6) analysis has shown promising results in the determination of SOM biogeochemical stability (e.g., Barré et al., 2016) and thus appears like a good candidate to fill this methodological gap. Originally developed for oil and gas exploration in sedimentary basins, the method was first applied to study soils with hydrocarbons contamination (Lafargue et al., 1998). RE was also shown to provide useful information on SOM originating from soil profiles worldwide (Disnar et al., 2003) and many studies on SOM characterization have been conducted, sometimes using RE analysis in conjunction with other methods like nuclear magnetic resonance (Albrecht et al., 2015), hydrocarbon analysis by gas chromatography (Di-Giovanni et al., 1998), infrared 
spectroscopy (Hetényi et al., 2006) or biochemical oxygen demand (Copard et al., 2006) to

104 determine the origin and/or decomposition stage of the organic matter (Hetényi et al., 2005;

105 Sebag et al., 2006).

106 More recently, RE6 results have been compared with respiration test or SOM fractions at the

107 plot (Gregorich et al., 2015) and the small landscape scale (Saenger et al., 2015) but in both

108 cases the analyses were restricted to superficial soil layers. Gillespie et al. (2014) have also

109 related thermal stability assessed by RE6 to respiration test and X-ray absorption near-edge

110 structure spectroscopy for cryosolic soil profiles (up to $75 \mathrm{~cm}$ ) in Northern Canada but only in

111 four hummocks. Finally, RE6 thermal analysis has been used to look at SOM dynamics in a

112 sample set with a large soil type variability and some deeper horizons (Sebag et al., 2016), but

113 without comparison to other methodologies.

114 The objective of this study was to properly "benchmark" RE6 thermal analysis with two

115 classical yet time-consuming methods for labile SOC pool estimation: a soil respiration test

116 isolating a respired-C fraction under controlled laboratory conditions and a physical SOC

117 fractionation scheme isolating a POM-C fraction. We selected soil samples from the French

118 forests monitoring network RENECOFOR at various depths. To our knowledge, this is the

119 first study considering such a large set of samples (covering a wide pedoclimatic variability),

120 including deep soil layers up to $0.8 \mathrm{~m}$. Our sample set thus included soil samples that

121 presumably contained very different proportions of the labile SOC pool. Because the

122 difference in size of the $\mathrm{C}$ pool estimated by the respiration test and the POM fractionation

123 (e.g., Haynes, 2005) and the previously observed correlations between stock of labile SOC

124 estimated by RE6 parameters and the POM fraction (Saenger et al., 2015) on one hand and

125 between cumulative C mineralized and a RE6 parameter (Gregorich et al., 2015) on the other

126 hand, we were expecting that: $1 /$ the results provided by the two classical methods would

127 differ quantitatively while the results from the three methods would be qualitatively 
comparable and correlated; 2 / we would be able to derive a significant quantitative relationship between RE6 parameters and the two classical indicators of the labile SOC pool.

\section{Material and methods}

\subsection{Sampling}

We considered forest soils samples from 53 permanent forest sites of the French national network for the long term monitoring of forest ecosystems ('RENECOFOR'), established in 1992 (Ulrich, 1995) by the National Forest Service (ONF; http://www.onf.fr/renecofor) as a part of the European ICP-FORESTS (http://icp-forests.net/) level 2 network (Fig. 1a). They were representative of a good portion the national variability in terms of climate (with MAP and MAT ranging between $703-1894 \mathrm{~mm}$ and $4.8-12.3^{\circ} \mathrm{C}$ respectively for the $1971-2000$ period), soil type (entic Podzol; eutric Cambisol/Calcisol; dystric Cambisol) (IUSS Working Group, 2015) and forest vegetation (coniferous - silver fir; Norway spruce; European larch; Scots pine — and deciduous — beech; oaks spp — stands). At each site, samples representing two soil layers were obtained $(0-10 \mathrm{~cm}$ and $40-80 \mathrm{~cm}$; Fig. 1b). Samples of the top soil layer

were composite, at each depth, of $5 \times 5$ sampling points located over a $5000 \mathrm{~m}^{2}$ plot, collected between 2007 and 2012 by digging a $50 \mathrm{~cm}$ wide soil profile (Ponette et al., 1997; Jonard et al., 2017). Samples of the deeper soil layer were composite from two soil pits located just outside the central plot and collected in 1994-1995 (Brêthes et al., 1997). The surface and deep samples thus originate from two different sampling campaigns. The deep samples were only collected once, during the first campaign, to limit perturbation on the monitoring plots. Basic soil parameters ( $\mathrm{pH}$ and texture) were determined by Ponette et al. (1997) and are reported as supplementary information (Table SI-A1).

Bulk soils were air-dried and stored in plastic buckets right after sampling. One liter of soil of each layer was retrieved for this study and sieved at $2 \mathrm{~mm}$ before analysis. 
155 Bulk $<2$ mm-sieved soil samples were ground $(<250 \mu \mathrm{m}$; ultra-centrifugal mill ZM 200,

156 Retsch Gmbh) and organic carbon and total nitrogen concentrations were determined by dry

157 combustion with an elemental analyzer (CHN NA 1500, Carlo Elba). Samples with

158 carbonates (total $\mathrm{CaCO}_{3}=3.5-835 \mathrm{~g} \cdot \mathrm{kg}^{-1}$ ) were first decarbonated following the same

159 protocol as Harris et al. (2001). Briefly, $30 \mathrm{mg}$ of ground samples were weighed in $5 \mathrm{~mm} \times 9$

$160 \mathrm{~mm}$ silver boats followed by the addition of $50 \mu \mathrm{L}$ of distilled water. The boats were put in a

161 glass bell jar, next to a beaker containing $100 \mathrm{~mL}$ of concentrated $\mathrm{HCl}\left(12 \mathrm{~mol} \cdot \mathrm{L}^{-1}\right)$. The air

162 in the jar was evacuated and samples let to sit in this HCl-saturated atmosphere to allow the

163 acid to dissolve water and hydrolyze the carbonates for $8 \mathrm{~h}$. Then, the decarbonated samples

164 were dried at $60^{\circ} \mathrm{C}$ in the silver boats for at least $48 \mathrm{~h}$. Silver boats were further placed in 10

$165 \mathrm{~mm} \times 10 \mathrm{~mm}$ tin boats and analyzed for $\mathrm{C}$ and $\mathrm{N}$.

166 POM fractions (see section 2.4.) were ground with a ball mill (mixer mill MM 200, Retsch

$167 \mathrm{Gmbh}$ ) or a mortar and pestle when the sample mass was less than $0.05 \mathrm{~g}$. Carbon

168 concentration was determined as for the bulk soil.

\subsection{Respiration test}

171 For each sample, $20 \mathrm{~g}$ of $2 \mathrm{~mm}$-sieved soil were transferred in a $120 \mathrm{~mL}$ glass-flask and re-

172 wetted at pF $2.5(-0.033 \mathrm{MPa})$, which had been previously determined using a 5 Bar pressure

173 plate extractor (\#1600, Soilmoisture Equipment Corp.). The flasks were fitted with aluminum

174 seals with PTFE-faced silicone septa to allow for headspace gas sampling and placed inside

175 an incubator (AE240 BIO EXPERT, Froilabo SAS) kept at $20{ }^{\circ} \mathrm{C}$ for 10 weeks following a

176 two-week period pre-incubation to allow the samples microbial activity to stabilize (data not

177 included). 
178 Headspace gases were sampled at 1 to 2 -week intervals during the 10 -week incubation period and $\mathrm{CO}_{2}$ concentrations were determined using an Agilent 490 micro-gas chromatograph equipped with the OpenLAB Chromatography Data System EZChrom software.

181 When $\mathrm{CO}_{2}$ concentrations had reached $2.5-3 \%$ or was expecting to do so before the next

182 measurement, and/or when the cap had been pierced with the needle four times, flasks were

183 opened and flushed with fresh and moist air to return $\mathrm{CO}_{2}$ concentrations to ambient levels to 184 avoid anoxia (while maintaining the moisture content), before returning them to the incubator.

185 The $\mathrm{CO}_{2}$ concentrations measured by the $\mathrm{GC}$ were converted in $\mu \mathrm{CO}_{2}-\mathrm{C}$-using equation 1:

$186 \mu \mathrm{g} \mathrm{C}-\mathrm{CO}_{2}=\mathrm{mmol}$ air $\times \mathrm{ppm} \mathrm{CO}_{2}(\mu \mathrm{mol} \mathrm{C} / \mathrm{mol}$ air $) \times 10^{-3}(\mathrm{~mol} / \mathrm{mmol}) \times 12(\mu \mathrm{g} \mathrm{C} / \mu \mathrm{mol} \mathrm{C})$

\section{7 (equation 1)}

188 where "mmol air" corresponds to the millimoles of air present in the flask and was calculated 189 with the ideal gas law (equation 2):

$\mathrm{n}=\mathrm{PV} / \mathrm{RT}=(1 \times 100) /(82.05 \times 293)$ (equation 2)

191 As a result, we multiplied our concentrations of $\mathrm{CO}_{2}$ expressed in percent by 499.16 to

192 convert them in $\mu \mathrm{g} \mathrm{C}-\mathrm{CO}_{2}$.

193 Finally, the 10 -week mineralizable SOC (respired-C) was expressed in $\mathrm{mg} \mathrm{CO}_{2}-\mathrm{C} \cdot \mathrm{g}^{-1} \mathrm{SOC}$ to

194 account for differences in the $\mathrm{C}$ content of the various layers and sites.

\subsection{Particle size and density SOC fractionation}

197 To isolate the particulate organic matter (POM) fraction, samples were first dried at $50{ }^{\circ} \mathrm{C}$ for

$19824 \mathrm{~h}$ before weighing $25 \mathrm{~g}$ and transferred them in polyethylene (PE) $250 \mathrm{~mL}$ flasks. We then

199 added $180 \mathrm{~mL}$ of $0.5 \%$ sodium hexametaphosphate solution and ten $5 \mathrm{~mm}$-diameter glass

200 beads before shaking the samples overnight (50 rpm; $16 \mathrm{~h})$ on an overhead shaker (Reax 2,

201 Heidolph), in order to breakdown soil aggregates. Samples were thoroughly rinsed over a 50-

$202 \mu \mathrm{m}$ mesh with deionized water. The $>50 \mu \mathrm{m}$ fraction was then transferred back to a dry PE 
203 flask with a sodium polytungstate (SPT) solution of density $=1.6 \pm 0.03 \mathrm{~g} \cdot \mathrm{cm}^{-3}$ (Golchin et 204 al., 1994; Crow et al., 2007) and the solution was added up to circa $180 \mathrm{~mL}$. The flasks were 205 shaken overhead by hand 10 times and samples were left overnight to settle down after the 206 cap of the flask was rinsed with the SPT solution. The floating material was collected with a 207 spatula and placed over a 50- $\mu \mathrm{m}$ mesh sieve. If necessary some SPT solution was added back 208 to the flask and the previous step was repeated. This time, samples were placed in a centrifuge 209 for 30 minutes to accelerate the separation (2750 rpm or $1250 \mathrm{~g}$, Six et al., 1998). The floating 210 material was again collected with the spatula or pipetted depending on the amount left. This 211 step was repeated if the light fraction was abundant. If not, samples were left to settle down 212 overnight before one last collection. The POM fraction on the sieve was thoroughly rinsed 213 with deionized water throughout the whole process. The sieves and fractions were then placed 214 in the oven at $50^{\circ} \mathrm{C}$ for $24 \mathrm{~h}$ before being weighed. To account for differences in the $\mathrm{C}$ 215 content of the different samples, we calculated the proportion of OC in the POM fraction 216 (POM-C), expressed in $\mathrm{g}$ POM-C $\cdot \mathrm{g}^{-1}$ total SOC.

2.5. Thermal analysis: Rock-Eval 6

219 The thermal analysis of the samples was performed with a Rock-Eval 6 turbo device (Vinci 220 Technologies, France). Details about the equipment have been previously published (Behar et 221 al., 2001). We adapted the procedure developed for the analysis of soil organic matter by 222 Disnar et al. (2003). Briefly, about 60 (20.7-62.1 depending on the sample's C content) mg of 223 ground sample were exposed to two consecutive thermal treatments, first in a pyrolysis oven $224\left(200-650{ }^{\circ} \mathrm{C}\right.$; thermal ramping rate of $30{ }^{\circ} \mathrm{C} \cdot \mathrm{min}^{-1}$; under $\mathrm{N}_{2}$ atmosphere) then in a 225 combustion oven $\left(300-850{ }^{\circ} \mathrm{C}\right.$; thermal ramping rate of $20^{\circ} \mathrm{C} \cdot \mathrm{min}^{-1}$; under laboratory air 226 atmosphere). At the beginning of the pyrolysis, there was an isothermal step (at $\left.200{ }^{\circ} \mathrm{C}\right)$ 227 during 180 seconds during which the free hydrocarbons (HC) were thermovaporized (S1 
peak). The pyrolysis effluents (mostly HC) were detected and quantified with flame ionization

229 detection, while $\mathrm{CO}$ and $\mathrm{CO}_{2}$ were quantified by infrared detection during both the pyrolysis

230 and oxidation stages (Fig. SI-A1).

231 Two standard RE6 parameters describing SOC bulk chemistry were determined: the hydrogen

232 and oxygen index values (HI and $\mathrm{OI}_{\mathrm{RE}}$ ). The $\mathrm{HI}$ index corresponds to the amount of

233 hydrocarbons formed during thermal pyrolysis of the sample (HC evolved between 200 and

$234650{ }^{\circ} \mathrm{C}$ minus the $\mathrm{S} 1$ peak) divided by the total SOC content of the sample and is expressed in

$235 \mathrm{mg} \mathrm{HC} \cdot \mathrm{g}^{-1} \mathrm{SOC}$. It describes the relative enrichment/depletion of SOC in hydrogen-rich

236 moieties. The $\mathrm{OI}_{\mathrm{RE} 6}$ index describes the relative oxidation status of SOC. It was calculated

237 using the equation proposed by Lafargue et al. (1998):

$238 \mathrm{OI}_{\mathrm{RE} 6}=16 / 28 \times \mathrm{OI}_{\mathrm{CO}}+32 / 44 \times \mathrm{OI}_{\mathrm{CO} 2} \quad$ (equation 3)

239 Where $\mathrm{OI}_{\mathrm{CO} 2}$ corresponds to the $\mathrm{CO}_{2}$ yielded during thermal pyrolysis of the sample between

240200 and $400^{\circ} \mathrm{C}$ divided by the total SOC of the sample and $\mathrm{OI}_{\mathrm{CO}}$ corresponds to the $\mathrm{CO}$

241 yielded during thermal pyrolysis between 200 and $400-650^{\circ} \mathrm{C}$ (wherever a minimum of CO

242 production is observed; in the absence of a minimum, the default upper-limit temperature is

243 set at $550{ }^{\circ} \mathrm{C}$ ) divided by the total SOC of the sample. Thus $\mathrm{OI}_{\mathrm{RE} 6}$ is expressed in $\mathrm{mg} \mathrm{O} \mathrm{O}_{2} \cdot \mathrm{g}^{-1}$

244 SOC.

245 We derived four additional RE6 parameters describing the thermal stability of SOC: (i)

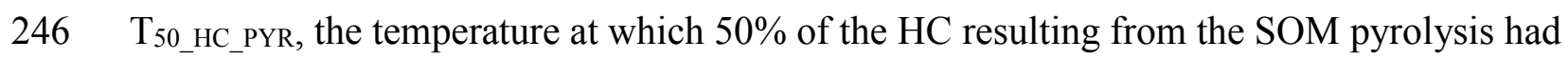

247 evolved (ii) the $\mathrm{T}_{50} \mathrm{CO}_{2} \mathrm{OX}$, the temperature at which $50 \%$ of the residual SOM was oxidized

248 to $\mathrm{CO}_{2}$ during the oxidation phase. Because the signal was noisy at the beginning of the

249 pyrolysis, we started the integration for $\mathrm{T}_{50 \_\mathrm{HC}} \mathrm{PYR}$ right after the $\mathrm{S} 1$ peak. For $\mathrm{T}_{50 \_} \mathrm{CO} 2_{-} \mathrm{OX}$, the

250 upper limit temperature for signal integration was set at $611^{\circ} \mathrm{C}$ to obtain a total $\mathrm{CO}_{2}$ signal

251 evolved from pure $\mathrm{OM}$ without interference of carbonates. Both these $\mathrm{T}_{50}$ temperature

252 parameters and the HI index have been previously shown as good thermal indicators of SOM 
253 biogeochemical stability (Gregorich et al., 2015; Barré et al., 2016). We also included two

254 thermal indices previously used in the literature: the (iii) R-index or (1 - R400), which 255 correspond to the integrated area of the $\mathrm{HC}$ thermogram above $400{ }^{\circ} \mathrm{C}$ over the total area of 256 the HC signal (Disnar et al., 2003; Sebag et al., 2016). The R-index estimates the proportion 257 of thermally stable SOC pool and varies between 0 and 1 . We hypothesized that the 258 proportion $(1-\mathrm{R}$-index) would approximate a thermally labile/intermediate (turnover $<20$ 259 years) SOC pool. Finally, using equation 4, we calculated the (iv) I-index, which is an 260 indicator of the preservation of thermally labile immature SOM (Sebag et al., 2016):

$261 \log _{10}((\mathrm{~A} 1+\mathrm{A} 2) / \mathrm{A} 3) \quad$ (equation 4$)$

262 where $\mathrm{A} 1+\mathrm{A} 2$ corresponds to the integrated area of the $\mathrm{HC}$ thermogram below $400{ }^{\circ} \mathrm{C}$ and 263 A3 the integrated area of the $\mathrm{HC}$ thermogram between $400{ }^{\circ} \mathrm{C}$ and $460{ }^{\circ} \mathrm{C}$.

264 Signal processing of the RE6 thermograms (signal integration and calculation of the 265 T50_HC_PYR, $\mathrm{T}_{50 \_} \mathrm{CO}_{2} \mathrm{OX}, \mathrm{R}$ and I indices) was performed with the R environment software v.3.3 266 (R Core Team, 2016) using the hyperSpec (Beleites and Sergo, 2015) and pracma (Borchers, 267 2015) R packages.

270 For RE6 analysis and the respiration test, samples with very low C content $(<0.2 \%)$ were not 271 considered as the carbon flux they produced during the incubation or the thermal analysis was 272 too low/too close to the limit of detection for reliable determination. This resulted in the 273 selection of $\mathrm{n}=46$ for the soil layer $40-80 \mathrm{~cm}($ total $\mathrm{n}=99)$.

274 The mean values of the variables derived from the SOC respiration test, fractionation and RE6 275 analysis for all layer depths were compared using standard non-parametric statistical methods 276 such as Kruskal Wallis test one-way ANOVA by ranks and Wilcoxon signed-rank test.

277 Relationships between the variables derived from the three methods were estimated using 
Spearman rank correlation as the data did not meet the assumption of normality. Correlation tests were first performed on the whole dataset $(\mathrm{n}=99)$ then within the $0-10 \mathrm{~cm}$ and the $40-$ $80 \mathrm{~cm}$ layers, the three soil types and the two vegetation types individually. All comparisons were considered significant at an alpha value $(\alpha)$ of 0.05 . A principal component of analysis (PCA) was performed to detect linear relations between parameters derived from the 3 methods. For that purpose, data were log-transformed, centered and scaled. Because the Iindex was negative in some instances, we added the equivalent of the smallest I-index value + 0.2 to all the I-index values to run the PCA. To determine the number of principal components to select, we looked at the percentage of the total variance explained and used a scree plot and Kaiser's criterion. To analyze the relationship between RE-based and the two classical indicators of the labile SOC pool, we used a simple linear regression model and relied on the Cook's distance to identify potential outliers. All statistical analyses were performed using R 3.3 (R Core Team, 2016) using the factoextra (Kassambara and Mundt, 2016) and Hmisc (Harrell et al., 2016) packages.

\section{Results}

\subsection{Respiration test}

The 10-week mineralizable SOC (respired-C) was expressed in $\mathrm{mg} \mathrm{CO}_{2}-\mathrm{C} \cdot \mathrm{g}^{-1} \mathrm{SOC}$ to account for differences in the $\mathrm{C}$ content of the various layers and sites. Over the course of the 10 -week incubation, the surface layer $(0-10 \mathrm{~cm})$ samples cumulatively respired on average 17 $\pm 7.2 \mathrm{mg} \mathrm{CO} 2-\mathrm{C} \cdot \mathrm{g}^{-1} \mathrm{SOC}$, while the deeper layer $(40-80 \mathrm{~cm})$ samples respired $13.4 \pm 6.9 \mathrm{mg}$ $\mathrm{CO}_{2}-\mathrm{C} \cdot \mathrm{g}^{-1} \mathrm{SOC}$ (Table 1$)$. There was a significant decrease in respired-C with depth $(p=$ 0.003), indicating a smaller size of the labile $\mathrm{C}$ pool in the deeper layers of our forest soils. Within each soil layer, the large standard deviation (around $7.0 \mathrm{mg} \mathrm{CO} 2-\mathrm{C} \cdot \mathrm{g}^{-1} \mathrm{SOC}$ ) illustrates an important inter-site variability. 
3.2. POM fractionation

305

The POM-C fraction (\% of total C) decreased by half between layers $0-10 \mathrm{~cm}$ and $40-80 \mathrm{~cm}$ with $22.6 \pm 7.3 \%$ and $11.0 \pm 6.1 \%$ respectively. This indicates a significantly $(p<0.001)$ smaller labile $\mathrm{C}$ pool in the deeper $(40-80 \mathrm{~cm})$ soil layer. POM-C ranged between $12.1-$ $43.0 \%$ and $2.5-33.6 \%$ in the $0-10 \mathrm{~cm}$ and $40-80 \mathrm{~cm}$ layers, respectively, illustrating again an important inter-site variability.

\subsection{RE6 thermal analysis}

There was a significant effect of depth on all RE6 parameters. Particularly, the two T50 parameters increased significantly $(p<0.001)$ with depth: $421 \pm 9{ }^{\circ} \mathrm{C}$ to $448 \pm 10{ }^{\circ} \mathrm{C}$ and 399 $\pm 9{ }^{\circ} \mathrm{C}$ to $431 \pm 18{ }^{\circ} \mathrm{C}$ (Table 1$)$, for $\mathrm{T}_{50}{ }_{-} \mathrm{HC}_{-} \mathrm{PYR}$ and $\mathrm{T}_{50} \mathrm{CO}_{-} \mathrm{O}$ ox respectively, corresponding to an increase in the thermal stability of total SOC (i.e. a relative decrease in the labile $\mathrm{C}$ pool and increase of the stable $\mathrm{C}$ pool). $\mathrm{OI}_{\mathrm{RE} 6}$ showed a similar increasing trend $(p<0.001)$ with depth $\left(225 \pm 37-439 \pm 138 \mathrm{mg} \mathrm{O} 2 \cdot \mathrm{g}^{-1}\right.$ total SOC; Table 1), reflecting a more oxidized SOC in the deeper layers. Conversely, HI decreased significantly $(p<0.001)$ with depth $(276 \pm 77-$ $133 \pm 34 \mathrm{mg} \mathrm{HC} \cdot \mathrm{g}^{-1}$ total SOC; Table 1$)$, suggesting a relative depletion of total SOC in $\mathrm{H}-$ rich moieties with increased soil depth. The proportion of thermally stable SOC R-index, also experienced a significant increase $(p<0.001)$ with depth (59-69\%; Table 1), while the Iindex decreased slightly $(0.17-0.11$; Table 1$)$.

\subsection{Correlations between methods}

3.4.1. For all samples

There were mainly significant and strong correlations between POM-C and the RE6 parameters (Table 2). Notably $\mathrm{T}_{50 \_} \mathrm{HC}_{-} \mathrm{PYR}, \mathrm{OI}_{\mathrm{RE} 6}$ and R-index all had a strong negative 
correlation with POM-C (Spearman $\rho=-0.73,-0.76$ and -0.69 respectively; Table 2; Fig. 3 ).

329 T50_CO2_Ox and HI moderately correlated with POM-C $(\rho=-0.56$ and 0.67$)$ and the I-index

330 had a weak positive relationship with POM-C $(\rho=0.35)$. I-index, T50_HC_PYR and R-index

331 were the only parameters that were significantly related to respired-C, with a weak correlation

$332(\rho=0.32, \rho=-0.26$ and -0.31 respectively; Table 2$)$. The two classical methods of

333 estimation of labile SOC (respired-C and POM-C) were weakly positively $(\rho=0.20$; Table 2 ;

334 Fig. SI-B1 a) and indeed only marginally $(p=0.051)$ related.

335 To describe the similarity or dissimilarity in the different indicators of SOC lability, we 336 conducted a principal components analysis (PCA). As shown by the correlation test, $\mathrm{T}_{50}$ 337 _HC_PYR and R-index on the one hand and $\mathrm{OI}_{\text {RE6 }}$ and $\mathrm{HI}$ on the other hand were highly 338 correlated ( $\rho=0.93$ and -0.92 respectively; Table 2$)$. We thus decided to conduct the PCA 339 using only the 6 following explanatory variables = respired-C; POM-C; HI; T50_CO2_ox; $\mathrm{T}_{50}$ 340 _HC_PYR; I-index). The first two principal components (PC) explained approximately $73 \%$ of 341 the total variance, with 53\% explained by the first and $20 \%$ explained by the second PC, 342 respectively (Fig. 2). PC1 clearly separated surface $(0-10 \mathrm{~cm})$ from deeper $(40-80 \mathrm{~cm})$ soil 343 samples. Along PC1, POM-C and HI showed moderate negative loadings ( -0.47 and -0.46 344 respectively; Table SI-B1) while $\mathrm{T}_{50} \mathrm{HC}_{-} \mathrm{PYR}$ and $\mathrm{T}_{50} \mathrm{CO}_{2} \mathrm{OX}$ had moderate positive loadings 345 (0.53 and 0.45; Table SI-B1). Respired-C and the I-index showed strong positive loadings 346 along PC2 (0.55 and 0.69; Table SI-B1), while they showed very weak negative loadings 347 along PC1. Samples from layers $0-10$ and 40-80 cm did not significantly differ along the 348 second PC. 3.4.2. For the $0-10 \mathrm{~cm}$ and $40-80 \mathrm{~cm}$ layer separately

351 These global correlations prompted us into looking at the influence of soil depth on the 352 different parameters. The paired correlations between the 8 parameters differed in surface $(0-$ 
$10 \mathrm{~cm}$ ) and deep (40-80 cm) layers (Table 2). Specifically, the respired-C in the surface

354 layers was weakly and negatively related to POM-C ( $\rho=-0.29$; Table 2$)$. Conversely in the 355 deep layers, respired-C and POM-C were moderately and positively correlated, as it would be 356 expected $\left(\rho=0.47\right.$; Table 2; Fig. SI-B1 a). In the surface layers, $\mathrm{HI}$ and $\mathrm{OI}_{\text {RE6 }}$ were also 357 moderately (negatively and positively, respectively; Table 2) correlated to respired-C, while 358 in the deep layers we observed again this negative and moderate correlation between

359 T50_HC_PYR and respired-C. For POM-C, we found the same negative correlations with $360 \mathrm{~T}_{50 \_\mathrm{HC} \_\mathrm{PYR}}$ and $\mathrm{OI}_{\mathrm{RE} 6}$ as in the "all samples" comparison but they were less strong $(\rho=-0.35$ 361 to -0.42 ; Table 2). In the surface layer, the $\mathrm{C} / \mathrm{N}$ ratio, $\mathrm{pH}$ and clay content had all moderate 362 and significant correlations with respired-C and $\mathrm{T}_{50 \_ \text {HC_PYR }}$ (Table 2). These correlations were 363 absent in the $40-80 \mathrm{~cm}$ layer.

364 We also looked at the evolutions of the correlations as a function of vegetation and soil types, 365 but there were no change as drastic as the ones we observed with depth (Table SI-C1). In both 366 cases the changes affected only the correlations between respired-C and the other parameters. 367 For instance, in coniferous plots, respired-C was weakly to moderately positively correlated to 368 clay content $(\rho=0.27)$ and $\mathrm{pH}(0.37)$ while those correlations were absent in deciduous plots 369 (Table SI-C1). For the soil types, POM-C and respired-C were moderately and positively correlated in Podzols (0.42) and eutric Cambisols (0.46) but not in dystric Cambisols.

371 Furthermore, in eutric Cambisols, respired-C was moderately and negatively correlated with 372 T50_CO2_Ox $(-0.54)$, R-index $(-0.50)$ and $\mathrm{pH}(-0.57$; Table SI-C1).

\section{Discussion} Unexpectedly the two classical indicators of the labile SOC fraction correlated only weakly

377 and marginally when considering all our samples. 
POM-C is considered as a labile SOC fraction (Wander, 2004; Haynes, 2005; von Lützow et

379 al., 2007), and we thus expected it would correlate significantly and strongly with the

380 respired-C fraction isolated by the 10-week laboratory respiration test. Indeed, in his review,

381 Haynes (2005) mentioned several studies reporting a positive and usually strong correlation

382 between the respired-C and the POM-C fractions, appearing to support that hypothesis.

383 However when carefully considering these papers (Janzen et al., 1992; Hassink, 1995;

384 Campbell et al., 1999a; Campbell et al., 1999b; Wander and Bidart, 2000) and others (Liang

385 et al., 2003; Hassan et al., 2016; Li et al., 2016), it emerged that the presented data were not

386 normalized by the total SOC concentration of the samples. Without normalization it could be

387 argued that the positive correlation between the POM-C and the respired-C fractions was in

388 fact driven by variations in total SOC concentration and not SOC biogeochemical stability. It

389 also prevented comparisons among studies, given the important difference in SOC

390 concentration.

391 The hypothesis of a positive correlation between the sizes of the labile SOC pool estimated by

392 respiration test and POM fractionation schemes has actually not been properly tested on

393 multiple sites, using SOC normalized data as it has been done in the present study. Indeed, the

394 few studies that have reported moderate to strong positive correlations between the sizes of

395 the labile SOC pool estimated by respiration test and POM fractionation were conducted on

396 similar soils under different management (e.g., Alvarez and Alvarez, 2000) or correlations

397 were made within sites (e.g., Janzen et al., 1992). When combining results from all sites, the

398 correlation appeared to be weaker and it can therefore be hypothesized that in our study the

399 weak and marginally significant correlation between POM-C and respired-C was partially due

400 to the large inter-sites variability of soil properties for our sample set (Table SI-A.1).

401 Finally, the labile SOC pools estimated by the two classical methods were so different in size

402 (i.e. the labile SOC pool estimated as respired-C was about an order of magnitude smaller 
403

than the one estimated as POM-C; Table 1) that it is not surprising that the correlation did not

404 hold specifically when introducing a lot of inter-sites variability. This constitutes another

405

406 explanation to the lack of correlation between these two indicators of the size of the labile $\mathrm{C}$ pool. The two methods appeared to measure different SOC fractions (i.e. different sizes) (Table 2 and Fig. 2) that correspond to different SOC lability (i.e. mean residence time).

\subsection{Relationships between RE6 parameters and POM-C and respired-C}

Our RE6 results agreed with previous observations of thermal indicators of SOC lability. For instance, Sebag et al. (2016) reported a trend of decreasing HI and increasing $\mathrm{OI}_{\mathrm{RE} 6}$ with soil depth. Trends of decreasing $\mathrm{HI}$ and increasing $\mathrm{T}_{50} \mathrm{CO}_{2}$ Ox were observed with increasing time since beginning of bare fallow experiments, which corresponded with a progressive decomposition of the labile SOC pool (Barré et al., 2016).

Our correlations between the RE6 parameters and the POM-C fraction were close to those previously reported by Saenger et al. (2015). They indeed obtained a moderate positive correlation $\left(\mathrm{R}^{2}=0.50\right)$ between the labile SOC pool stocks derived from a SOC fractionation scheme isolating POM-C, and the thermally labile SOC pool stocks derived from RE6 indices. We found a similar strong positive correlation between the proportion of labile SOC (1-R-index) and POM-C. The strong relationship between $\mathrm{T}_{50} \mathrm{HC}_{-} \mathrm{PYR}$ and R-index could likely be explained as $\mathrm{T}_{50} \mathrm{HC}_{\mathrm{H}} \mathrm{PYR}$ for our samples were very close to the $400{ }^{\circ} \mathrm{C}$ threshold used for the calculation of the R-index. As hypothesized we were able to derive a quantitative relationship between some of our RE6 parameters and POM-C (Fig. SI-B1 b-d). The best model was obtained for $\mathrm{T}_{50 \_H C}$ PYR $\left(\mathrm{R}^{2}=0.52\right.$; Fig. 3$)$, while HI, R-index and $\mathrm{OI}_{\mathrm{RE} 6}$ were still moderately good predictors of POM-C $\left(\mathrm{R}^{2}=0.42-0.47\right.$ (Fig. SI-B1 b-d).

\section{Nevertheless no strong relationship between respired-C and the other parameters could be} established. Our correlations between the RE6 parameters and respired-C were smaller than 
428 those previously reported by Gregorich et al. (2015). This could be explained by the fact that

429 their study was, by design, very restricted in terms of its soil properties variability and also

430 only considered surface soils $(0-10 \mathrm{~cm})$, in which the $\mathrm{C} / \mathrm{N}$ ratios were around 10 .

431 Previous studies have also demonstrated that RE6 can be used to look at changes in the size of 432 the SOC labile pools with time. For instance, RE6 was able to describe the decrease in the

433 labile SOC pool in long-term bare fallows (Barré et al., 2016). Besides, RE6 captured

434 differences in the size of the labile SOC pools in various land-uses and soil types over a small 435 landscape (Saenger et al., 2015). Our results thus contradict the conclusions from Schiedung 436 et al. (2017) who found no relationship between the thermally labile SOC $\left(200-400{ }^{\circ} \mathrm{C}\right)$ and 437 the $\mathrm{C}$ in the POM fractions. The latter (free and occluded POM-obtained by sonication) 438 were indeed more stable at lower oxidation temperatures $\left(300-350{ }^{\circ} \mathrm{C}\right)$ than the mineral439 associated fraction. However, their analytical method was different from RE6 protocols: the 440 thermal analysis they used was entirely realized under aerobic conditions (oxidation only), 441 their temperature range was limited (only up to $400{ }^{\circ} \mathrm{C}$ ) and they used a $50-100{ }^{\circ} \mathrm{C}$ 442 temperature step every 15 minutes rather than a constant thermal ramping rate (standard in 443 most thermal studies). For all these reasons, it is likely that their thermal indices differ greatly 444 from our RE6-derived parameters. Moreover their study was based on topsoils $(0-10 \mathrm{~cm})$ of 445 only three study sites.

446 The good approximation of the POM-C fraction by RE6 we reported constitutes a very 447 promising result. POM-C mean residence time $(<20$ years in temperate conditions in the 448 absence of an important charcoals contribution; e.g., Trumbore and Zheng, 1996; Balesdent, 449 1996; Balesdent et al., 1998; Baisden et al., 2002; Schrumpf and Kaiser, 2015) and its size (11 450 to $23 \%$ of total SOC in this study) are much larger than the one of the respired-C fraction, and 451 is thus more meaningful regarding SOC stock evolutions upon changes of land management. 
452 This suggests that RE6 could be used to determine the size of the labile SOC pool with a

453 decadal mean residence time.

4.3. Effects of depth on correlations between the three methods estimating labile SOC

Labile SOC content usually decreases with depth (e.g., Lorenz and Lal, 2005; Jenkinson et al.,

2008). Such a trend was observed with the three methods used in the present study. Indeed,

460 the expected decrease in the size the labile SOC pool. Concurrently, OIRE6 increased with

461 depth, confirming the increase in SOC oxidative state with increasing decomposition

462 (Hockaday et al., 2009; von Lützow and Kögel-Knabner, 2010; Hockaday et al., 2015).

463 But more importantly, depth affected the correlations between the methods. The lack of

464 correlation between two classical indicators of the labile SOC fraction previously mentioned

465 appeared to originate from opposite trends in the surface and deep layers. In the $0-10 \mathrm{~cm}$

466 layer we observed a surprising negative (but weak) correlation between respired-C and POM-

467 C while the expected positive and moderate correlation between the two indicators was found 468 only in the deep layers. The differences in the sign of the correlations between respired-C and 469 POM-C in the two considered layers $(0-10 \mathrm{~cm}$ and $40-80 \mathrm{~cm})$ may be related to pedological

470 factors that can limit SOC mineralization in surface horizons. Indeed, the high $\mathrm{C} / \mathrm{N}$ ratio

471 found in the surface layer (Table SI-A1) is far from the expected $\mathrm{C} / \mathrm{N}$ of the microorganisms

472 and this lack of N may limit SOC respiration. Similarly, surface layers are on average more

473 acidic (Table SI-A1) than deep layers which can also reduce SOC respiration. We could

474 hypothesize that respired-C and POM-C correlate only when environmental conditions do not

475 limit SOC mineralization explaining the absence of correlation in the acidic N-poor $0-10 \mathrm{~cm}$

476 layer. The significant correlations observed between respired-C and the $\mathrm{C} / \mathrm{N}$ ratio, $\mathrm{pH}$ and the 
clay content in the surface layer (Table 2) supports that hypothesis. This opposite behavior in the two layers also affected $\mathrm{T}_{50}{ }_{\mathrm{HC}} \mathrm{PY}$ PY, which was not significantly correlated to respired-C in the surface layer while the two parameters were moderately and negatively correlated in the 40-80 cm layer (Table 2). These observations matched those from Peltre et al. (2013) who reported conflicting relationships between the parameter DSC-T50 (temperature at which half of the energy is released in differential scanning calorimetry) and mean soil respiration rates in two sets of high and low SOC content. Their DSC-T50 values were indeed negatively correlated with the respiration values for the low-C soils, whereas there was only a marginal positive correlation between the two parameters for the high-C soils. Their two groups were characterized by soil properties similar to our $0-10$ and $40-80 \mathrm{~cm}$ layers: their low-C set consisted of samples with a higher $\mathrm{pH}$ and lower mean $\mathrm{C} / \mathrm{N}$ ratio than those of the high-C. Similarly to our $0-10 \mathrm{~cm}$ samples, soils in their high- $\mathrm{C}$ set had a greater $\mathrm{C}$ concentration than those in the low-C set for similar clay contents (Table SI-A1). This would also explain why our results differ from those of Gregorich et al. (2015). In the deep layer, in which the $\mathrm{C} / \mathrm{N}$ ratios are closer to those reported by Gregorich et al. (2015), we observed the same positive correlation they reported albeit less strong.

Vegetation and soil types did not seem to have affected the correlations between the three methods we tested as much as depth did. However, these environmental factors are likely drivers of the size labile SOC pool as they have been shown to significantly influence RE6 parameters (e.g., Disnar et al., 2003; Sebag et al., 2006).

\subsection{Towards high-throughput information on SOC biogeochemical stability using RE6} analysis

Respiration tests and POM fractionation schemes are both time consuming, thus limiting the number of samples and/or replicates that are analyzed. With the RE6 set-up used in this study, 
about 20 samples per day can be analyzed, and it requires only limited operator interventions

503 (soil weighing and routine supervision of the RE6 analyzer).

504 The lack of normalization in many studies using respiration tests and POM fractionation is an

505 important issue and it should be recommended for further studies to include normalized data

506 (\% of TOC) when presenting their results. Moreover, despite the fact that POM-C and

507 respired-C are considered as standard estimates of the labile SOC pool, the temperature and/or

508 duration of incubations often varied from one study to the other. Similarly for the POM-C

509 fraction, the density of the solution used for the flotation may drastically differ among studies.

510 This makes data comparison almost impossible. In that regard, while the harmonization of

511 RE6 programs would probably be much easier to implement than respiration tests or POM

512 fractionation protocols as the number of users is still limited, protocol standardization is an

513 important and pressing goal to achieve and this rather quickly as the method starts to gain

514 interest.

515 RE6 analysis is thus a rapid technique that captures differences in the labile SOC pool as well

516 as other classical techniques. While the understanding of the underlying processes linking

517 SOC thermal stability observed with RE6 and the laboratory or in-situ biogeochemical

518 stability of SOC is not fully uncovered and further studies are needed, RE6 analysis appears

519 like a very promising method to provide quick and inexpensive information on the labile SOC

520 pool. Hence, it could constitute a standard method to complement C stock measurements in

521 soil monitoring programs.

\section{Acknowledgments}

525 This work was supported by the Agence de l'environnement et de la maîtrise de l'énergie

526 (ADEME) [APR REACCTIF, piCaSo project] and Campus France [PRESTIGE-2015-3- 
0008]. We thank M. Bryant, S. Cecchini, L. Le Vagueresse, J. Mériguet and F. Savignac and for their technical support. The authors acknowledge two anonymous reviewers for their time and valuable comments on the manuscript.

\section{Reference list}

Albrecht, R., Sebag, D., Verrecchia, E., 2015. Organic matter decomposition: Bridging the gap between Rock-Eval pyrolysis and chemical characterization (CPMAS ${ }^{13} \mathrm{C} \mathrm{NMR}$ ). Biogeochemistry 122, 101-111.

Alvarez, R., Alvarez, C.R., 2000. Soil organic matter pools and their associations with carbon mineralization kinetics. Soil Science Society of America Journal 64, 184-189.

Baisden, W.T., Amundson, R., Cook, A.C., Brenner, D.L., 2002. Turnover and storage of C and $\mathrm{N}$ in five density fractions from California annual grassland surface soils. Global Biogeochemical Cycles 16, 64-61; 64-16.

Balesdent, J., 1996. The significance of organic separates to carbon dynamics and its modelling in some cultivated soils. European Journal of Soil Science 47, 485-494.

Balesdent, J., Besnard, E., Arrouays, D., Chenu, C., 1998. The dynamics of carbon in particlesize fractions of soil in a forest-cultivation sequence. Plant and Soil 201, 49-57.

Barré, P., Plante, A.F., Cécillon, L., Lutfalla, S., Baudin, F., Christensen, B.T., Eglin, T., Fernandez, J.M., Houot, S., Kätterer, T., Le Guillou, C., Macdonald, A., van Oort, F., Chenu, C., 2016. The energetic and chemical signatures of persistent soil organic matter. Biogeochemistry 130, 1-12.

Behar, F., Beaumont, V., Penteado, D.B., 2001. Rock-Eval 6 technology: Performances and developments. Oil \& Gas Science and Technology - Rev.IFP 56, 111-134.

Beleites, C., Sergo, V., 2015. hyperSpec: A Package to Handle Hyperspectral Data Sets in R. 
552 Borchers, H.W., 2015. Pracma: Practical numerical math functions.

553 Brêthes, A., Ulrich, E., Lanier, M., 1997. RENECOFOR : Caractéristiques Pédologiques Des 554102 Peuplements Du Réseau : Observations De 1994/95. Office national des forêts, 555 Département des recherches techniques, Fontainebleau, France, 573 pp.

556 Campbell, C.A., Biederbeck, V.O., Wen, G., Zentner, R.P., Schoenau, J., Hahn, D., 1999a. 557 Seasonal trends in selected soil biochemical attributes: Effects of crop rotation in the 558 semiarid prairie. Canadian Journal of Soil Science 79, 73-84.

559 Campbell, C.A., Lafond, G.P., Biederbeck, V.O., Wen, G., Schoenau, J., Hahn, D., 1999 b.

560 Seasonal trends in soil biochemical attributes: Effects of crop management on a black 561 chernozem. Canadian Journal of Soil Science 79, 85-97.

562 Copard, Y., Di-Giovanni, C., Martaud, T., Albéric, P., Olivier, J., 2006. Using Rock-Eval 6 563 pyrolysis for tracking fossil organic carbon in modern environments: Implications for the 564 roles of erosion and weathering. Earth Surface Processes and Landforms 31, 135-153.

565 Crow, S.E., Swanston, C.W., Lajtha, K., Brooks, J.R., Keirstead, H., 2007. Density 566 fractionation of forest soils: Methodological questions and interpretation of incubation 567 results and turnover time in an ecosystem context. Biogeochemistry 85, 69-90.

568 Di-Giovanni, C., Disnar, J.R., Bichet, V., Campy, M., Guillet, B., 1998. Geochemical 569 characterization of soil organic matter and variability of a postglacial detrital organic supply 570 (Chaillexon lake, France). Earth Surface Processes and Landforms 23, 1057-1069.

571 Disnar, J.-R., Guillet, B., Keravis, D., Di-Giovanni, C., Sebag, D., 2003. Soil organic matter 572 (SOM) characterization by Rock-Eval pyrolysis: Scope and limitations. Organic 573 Geochemistry 34, 327-343.

574 Feng, W., Shi, Z., Jiang, J., Xia, J., Liang, J., Zhou, J., Luo, Y., 2016. Methodological 575 uncertainty in estimating carbon turnover times of soil fractions. Soil Biology and $576 \quad$ Biochemistry 100, 118-124. 
Gillespie, A.W., Sanei, H., Diochon, A., Ellert, B.H., Regier, T.Z., Chevrier, D., Dynes, J.J., Tarnocai, C., Gregorich, E.G., 2014. Perennially and annually frozen soil carbon differ in their susceptibility to decomposition: Analysis of subarctic earth hummocks by bioassay, XANES and pyrolysis. Soil Biology and Biochemistry 68, 106-116.

Golchin, A., Oades, J.M., Skjemstad, J.O., Clarke, P., 1994. Study of free and occluded particulate organic matter in soils by solid state ${ }^{13} \mathrm{C} \mathrm{CP} / \mathrm{MAS}$ NMR spectroscopy and scanning electron microscopy. Australian Journal of Soil Research 32, 285-309.

Gregorich, E.G., Gillespie, A.W., Beare, M.H., Curtin, D., Sanei, H., Yanni, S.F., 2015. Evaluating biodegradability of soil organic matter by its thermal stability and chemical composition. Soil Biology and Biochemistry 91, 182-191.

Harrell, F.E.J., Dupont, C., and others, 2016. Hmisc: Harrell miscellaneous.

Harris, D., Horwáth, W.R., van Kessel, C., 2001. Acid fumigation of soils to remove carbonates prior to total organic carbon or CARBON-13 isotopic analysis. Soil Science Society of America Journal 65, 1853-1856.

Hassan, W., Bashir, S., Ahmed, N., Tanveer, M., Shah, A.N., Bano, R., David, J., 2016. Labile organic carbon fractions, regulator of $\mathrm{CO}_{2}$ emission: Effect of plant residues and water regimes. CLEAN - Soil, Air, Water 44, 1358-1367.

Hassink, J., 1995. Density fractions of soil macroorganic matter and microbial biomass as predictors of C and N mineralization. Soil Biology and Biochemistry 27, 1099-1108.

Haynes, R.J., 1986. Chapter 2 - the Decomposition Process: Mineralization, Immobilization, Humus Formation, and Degradation. In: Haynes, R.J. (Ed.), Mineral Nitrogen in the PlantSoil System. Academic Press, pp. 52-126.

Haynes, R.J., 2005. Labile organic matter fractions as central components of the quality of agricultural soils: An overview. Advances in Agronomy 85, 221-268. 
601 Hetényi, M., Nyilas, T., Sajgó, C., Brukner-Wein, A., 2006. Heterogeneous organic matter

602 from the surface horizon of a temperate zone marsh. Organic Geochemistry 37, 1931-1942.

603 Hetényi, M., Nyilas, T., Tóth, T.M., 2005. Stepwise Rock-Eval pyrolysis as a tool for typing

604 heterogeneous organic matter in soils. Journal of Analytical and Applied Pyrolysis 74, 45-

60554.

606 Hockaday, W.C., Gallagher, M.E., Masiello, C.A., Baldock, J.A., Iversen, C.M., Norby, R.J.,

607 2015. Forest soil carbon oxidation state and oxidative ratio responses to elevated $\mathrm{CO}_{2}$.

608 Journal of Geophysical Research: Biogeosciences 120, 1797-1811.

609 Hockaday, W.C., Masiello, C.A., Randerson, J.T., Smernik, R.J., Baldock, J.A., Chadwick,

610 O.A., Harden, J.W., 2009. Measurement of soil carbon oxidation state and oxidative ratio by

$611{ }^{13} \mathrm{C}$ nuclear magnetic resonance. Journal of Geophysical Research 114.

612 IUSS Working Group, 2015. World reference base for soil resources 2014 (update 2015),

613 international soil classification system for naming soils and creating legends for soil maps.

614 World Soil Resources Reports No. 106. FAO, Rome.

615 Janzen, H.H., Campbell, C.A., Brandt, S.A., Lafond, G.P., Townley-Smith, L., 1992. Light-

616 fraction organic matter in soils from long-term crop rotations. Soil Science Society of

617 America Journal 56, 1799-1806.

618 Jenkinson, D.S., Poulton, P.R., Bryant, C., 2008. The turnover of organic carbon in subsoils.

619 Part 1. Natural and bomb radiocarbon in soil profiles from the Rothamsted long-term field

620 experiments. European Journal of Soil Science 59, 391-399.

621 Jonard, M., Nicolas, M., Coomes, D.A., Caignet, I., Saenger, A., Ponette, Q., 2017. Forest

622 soils in France are sequestering substantial amounts of carbon. Science of The Total

623 Environment 574, 616-628.

624 Kassambara, A., Mundt, F., 2016. Factoextra: Extract and visualize the results of multivariate 625 data analyses. 
Lafargue, E., Marquis, F., Pillot, D., 1998. Rock-Eval 6 applications in hydrocarbon exploration, production, and soil contamination studies. Oil \& Gas Science and Technology - Revue IFP 53, 421-437.

Li, X.J., Li, X.R., Wang, X.P., Yang, H.T., 2016. Changes in soil organic carbon fractions after afforestation with xerophytic shrubs in the tengger desert, northern china. European Journal of Soil Science 67, 184-195.

Liang, B.C., McConkey, B.G., Schoenau, J., Curtin, D., Campbell, C.A., Moulin, A.P., Lafond, G.P., Brandt, S.A., Wang, H., 2003. Effect of tillage and crop rotations on the light fraction organic carbon and carbon mineralization in chernozemic soils of Saskatchewan. Canadian Journal of Soil Science 83, 65-72.

Lorenz, K., Lal, R., 2005. The depth distribution of soil organic carbon in relation to land use and management and the potential of carbon sequestration in subsoil horizons. Advances in Agronomy 88, 35-66.

Luo, Y., Ahlström, A., Allison, S.D., Batjes, N.H., Brovkin, V., Carvalhais, N., Chappell, A., Ciais, P., Davidson, E.A., Finzi, A., Georgiou, K., Guenet, B., Hararuk, O., Harden, J.W., He, Y., Hopkins, F., Jiang, L., Koven, C., Jackson, R.B., Jones, C.D., Lara, M.J., Liang, J., McGuire, A.D., Parton, W., Peng, C., Randerson, J.T., Salazar, A., Sierra, C.A., Smith, M.J., Tian, H., Todd-Brown, K.E.O., Torn, M., van Groenigen, K.J., Wang, Y.P., West, T.O., Wei, Y., Wieder, W.R., Xia, J., Xu, X., Xu, X., Zhou, T., 2016. Toward more realistic projections of soil carbon dynamics by earth system models. Global Biogeochemical Cycles $30,40-56$.

Peltre, C., Fernández, J.M., Craine, J.M., Plante, A.F., 2013. Relationships between biological and thermal indices of soil organic matter stability differ with soil organic carbon level. SSSAJ 77, 2020-2028. 
650 Ponette, Q., Ulrich, E., Brêthes, A., Bonneau, M., Lanier, M., 1997. RENECOFOR - Chimie

651 Des Sols Dans Les 102 Peuplements Du Réseau : Campagne De Mesures 1993-95. ONF,

652 Département des recherches techniques, Fontainebleau, France, 427 pp.

653 R Core Team, 2016. R: A language and environment for statistical computing.

654 Saenger, A., Cécillon, L., Poulenard, J., Bureau, F., De Daniéli, S., Gonzalez, J., Brun, J., 655 2015. Surveying the carbon pools of mountain soils: A comparison of physical fractionation 656 and Rock-Eval pyrolysis. Geoderma 241-242, 279-288.

657 Schiedung, M., Don, A., Wordell-Dietrich, P., Alcántara, V., Kuner, P., Guggenberger, G., 658 2017. Thermal oxidation does not fractionate soil organic carbon with differing biological 659 stabilities. Journal of Plant Nutrition and Soil Science 180, 18-26.

660 Schrumpf, M., Kaiser, K., 2015. Large differences in estimates of soil organic carbon 661 turnover in density fractions by using single and repeated radiocarbon inventories. 662 Geoderma 239-240, 168-178.

663 Sebag, D., Disnar, J.R., Guillet, B., Di Giovanni, C., Verrecchia, E.P., Durand, A., 2006.

664 Monitoring organic matter dynamics in soil profiles by 'Rock-Eval pyrolysis': Bulk 665 characterization and quantification of degradation. European Journal of Soil Science 57, $666 \quad 344-355$.

667 Sebag, D., Verrecchia, E.P., Cécillon, L., Adatte, T., Albrecht, R., Aubert, M., Bureau, F., 668 Cailleau, G., Copard, Y., Decaens, T., Disnar, J.-R., Hetényi, M., Nyilas, T., Trombino, L., 669 2016. Dynamics of soil organic matter based on new Rock-Eval indices. Geoderma 284, $670 \quad 185-203$.

671 Six, J., Elliott, E.T., Paustian, K., Doran, J.W., 1998. Aggregation and soil organic matter 672 accumulation in cultivated and native grassland soils. Soil Science Society of America 673 Journal 62, 1367-1377. 
674 Trumbore, S.E., Zheng, S., 1996. Comparison of fractionation methods for soil organic matter

$675 \quad{ }^{14} \mathrm{C}$ analysis. Radiocarbon 38, 219-229.

676 Trumbore, S.E., Chadwick, O.A., Amundson, R., 1996. Rapid exchange between soil carbon

677 and atmospheric carbon dioxide driven by temperature change. Science 272, 393-396.

678 Ulrich, E., 1995. Le réseau RENECOFOR : Objectifs et réalisation. Revue forestière française

$679 \quad 47,107-124$.

680 von Lützow, M., Kögel-Knabner, I., 2010. Response to the concept paper: 'What is

681 recalcitrant soil organic matter?' by Markus Kleber. Environmental Chemistry 7, 333-335.

682 von Lützow, M., Kögel-Knabner, I., Ekschmitt, K., Flessa, H., Guggenberger, G., Matzner,

683 E., Marschner, B., 2007. SOM fractionation methods: Relevance to functional pools and to

684 stabilization mechanisms. Soil Biology and Biochemistry 39, 2183-2207.

685 Wander, M.M., Bidart, M.G., 2000. Tillage practice influences on the physical protection, 686 bioavailability and composition of particulate organic matter. Biology and Fertility of Soils $687 \quad 32,360-367$.

688 Wander, M., 2004. Soil Organic Matter Fractions and their Relevance to Soil Function. In:

689 Magdoff, F., Weil, R.R. (Eds.), Soil Organic Matter in Sustainable Agriculture. CRC Press, 690 pp. 67-102.

691 


\section{Figure captions}

693 Fig. 1. (a) Location of the 53 study sites front the French national network for the long term

694 monitoring of forest ecosystems (RENECOFOR); (b) Number of samples by depths and

695 analyses realized. Plot locations are also available via the Interactive Map Viewer.

696

697 Fig. 2. Biplot of a principal components analysis (PCA) showing the loadings of the 6

698 parameters estimating the labile SOC (red arrows) and the 99 soil samples for the two layers

$699(0-10 \mathrm{~cm}, \mathrm{n}=53 ; 40-80 \mathrm{~cm}, \mathrm{n}=46)$ along the first two principal component axes (PC1 and 700 PC2). The 95\% ellipses for both soil layers were added for information; the circle in the 701 center corresponds to the circle of correlations.

702

703 Fig. 3. The proportion of OC in the POM fraction (POM-C) as a function of $\mathrm{T}_{50 \_H C}$ PYR (the 704 temperature at which 50\% of the HC pyrolysis effluents have evolved) for all samples ( $\mathrm{n}=$ $70599 ;$ surface $=0-10 \mathrm{~cm}$ and deep $=40-80 \mathrm{~cm})$. 


\section{Figure captions}

708 Fig. 1. (a) Location of the 53 study sites front the French national network for the long term

709 monitoring of forest ecosystems (RENECOFOR); (b) Number of samples by depths and

710 analyses realized. Plot locations are also available via the Interactive Map Viewer.

711

712 Fig. 2. Biplot of a principal components analysis (PCA) showing the loadings of the 6

713 parameters estimating the labile SOC (red arrows) and the 99 soil samples for the two layers

$714(0-10 \mathrm{~cm}, \mathrm{n}=53 ; 40-80 \mathrm{~cm}, \mathrm{n}=46)$ along the first two principal component axes $(\mathrm{PC} 1$ and

715 PC2). The 95\% ellipses for both soil layers were added for information; the circle in the

716 center corresponds to the circle of correlations.

717

718 Fig. 3. The proportion of OC in the POM fraction (POM-C) as a function of $\mathrm{T}_{50 \_H C \_P Y R}($ the

719 temperature at which $50 \%$ of the $\mathrm{HC}$ pyrolysis effluents have evolved) for all samples $(\mathrm{n}=$ $72099 ;$ surface $=0-10 \mathrm{~cm}$ and deep $=40-80 \mathrm{~cm})$. 


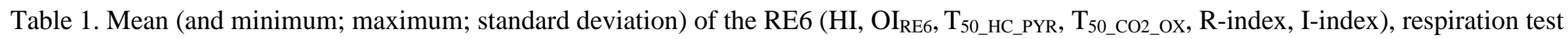
(10-week mineralizable C, respired-C) and POM fractionation (POM-C) parameters, as well as the bulk SOC content for each soil layer (0-10 and $40-80 \mathrm{~cm}$ ) of the 53 RENECOFOR plots.

\begin{tabular}{|c|c|c|c|c|c|c|c|c|c|c|c|c|c|c|c|c|c|c|c|}
\hline \multirow[b]{2}{*}{$0-10 \mathrm{~cm}$} & \multirow{2}{*}{$\mathrm{n}$} & \multicolumn{2}{|c|}{$\begin{array}{l}\mathrm{HI}(\mathrm{mg} \mathrm{HC} \\
\text { / g TOC) }\end{array}$} & \multicolumn{2}{|c|}{$\begin{array}{c}\mathrm{OI}_{\mathrm{RE} 6}(\mathrm{mg} \\
\mathrm{O}_{2} / \mathrm{g} \\
\mathrm{TOC})\end{array}$} & \multicolumn{2}{|c|}{$\begin{array}{c}\mathrm{T}_{50 \_ \text {HC_PYR }} \\
\left({ }^{\circ} \mathrm{C}\right)\end{array}$} & \multicolumn{2}{|c|}{$\begin{array}{c}\mathrm{T}_{50 \_\mathrm{CO} 2 \_\mathrm{OX}} \\
\left({ }^{\circ} \mathrm{C}\right)\end{array}$} & \multicolumn{2}{|c|}{$\begin{array}{l}\text { R-index } \\
\text { (\% SOC) }\end{array}$} & \multicolumn{2}{|c|}{ I-index } & \multicolumn{2}{|c|}{$\begin{array}{c}\text { Respired-C } \\
\left(\mathrm{mg} \mathrm{CO}_{2}-\mathrm{C} /\right. \\
\mathrm{g} \mathrm{SOC})\end{array}$} & \multicolumn{2}{|c|}{$\begin{array}{c}\text { POM-C (\% } \\
\text { SOC) }\end{array}$} & \multicolumn{2}{|c|}{$\begin{array}{l}\text { SOC }(\%) \\
\text { (bulk soil) }\end{array}$} \\
\hline & & 276 & $\begin{array}{r}(161 ; \\
443 ; \\
77)\end{array}$ & 225 & $\begin{array}{r}(161 ; \\
288 ; \\
37)\end{array}$ & 421 & $\begin{array}{r}(400 ; \\
439 ; \\
9)\end{array}$ & 399 & $\begin{array}{r}(382 ; \\
422 ; \\
9)\end{array}$ & 59 & $\begin{array}{r}(50 ; \\
68 ; \\
4)\end{array}$ & 0.17 & $\begin{array}{r}(0.00 \\
0.32 \\
0.07)\end{array}$ & 17.0 & $\begin{array}{r}(4.4 ; \\
33.7 \\
7.2)\end{array}$ & 22.6 & $\begin{array}{r}(12.1 ; \\
43.0 ; \\
7.3)\end{array}$ & 5.1 & $\begin{array}{r}(1.2 ; \\
15.1 ; \\
2.7)\end{array}$ \\
\hline $40-80 \mathrm{~cm}$ & 46 & 133 & $\begin{array}{r}(75 ; \\
202 ; \\
34)\end{array}$ & 439 & $\begin{array}{l}(236 ; \\
875 ; \\
138)\end{array}$ & 448 & $\begin{array}{r}(421 ; \\
480 \\
10)\end{array}$ & 431 & $\begin{array}{r}(390 ; \\
470 ; \\
18)\end{array}$ & 69 & $\begin{array}{r}(59 ; \\
79 ; \\
5)\end{array}$ & 0.11 & $\begin{array}{r}(-0.18 \\
0.39 \\
0.14)\end{array}$ & 13.4 & $\begin{array}{r}(3.6 ; \\
32.2 ; \\
6.9)\end{array}$ & 11.0 & $\begin{array}{r}(2.5 \\
33.6 \\
6.1)\end{array}$ & 0.9 & $\begin{array}{l}(0.2 ; \\
3.9 ; \\
0.8)\end{array}$ \\
\hline
\end{tabular}


Table 2. Spearman correlation coefficients between 10-week mineralizable SOC (respired-C), the proportion of OC in the POM fraction (POMC), the RE6 parameters and the C/N ratio, $\mathrm{pH}$ and clay content of the bulk soil, for both the $0-10 \mathrm{~cm}(\mathrm{n}=53)$ and $40-80 \mathrm{~cm}(\mathrm{n}=46)$ layers and each layer individually. Significance is indicated as follows: ***: $p<0.001 ; * *: p<0.01 ; *: p<0.05$. The very high correlations are marked in bold.

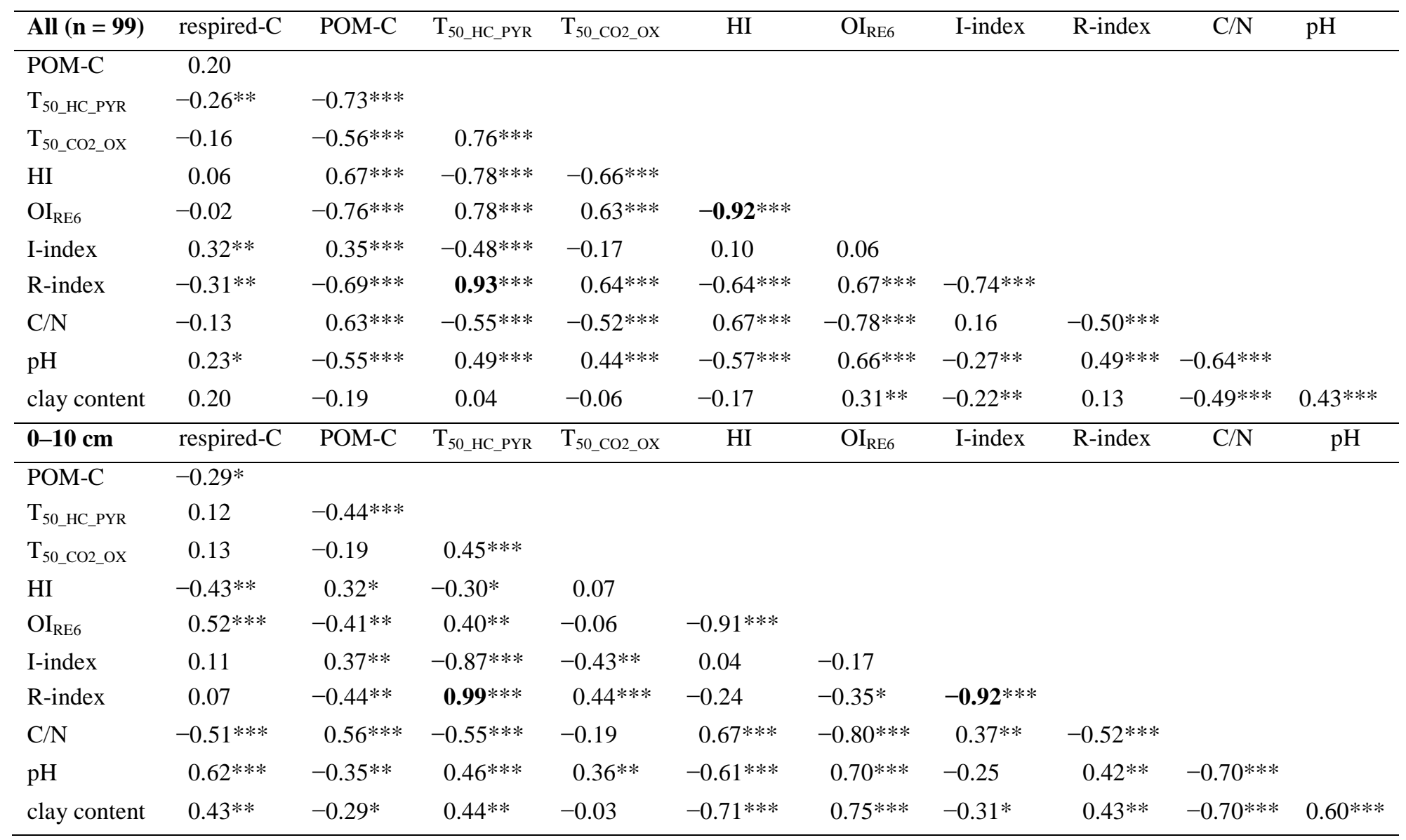




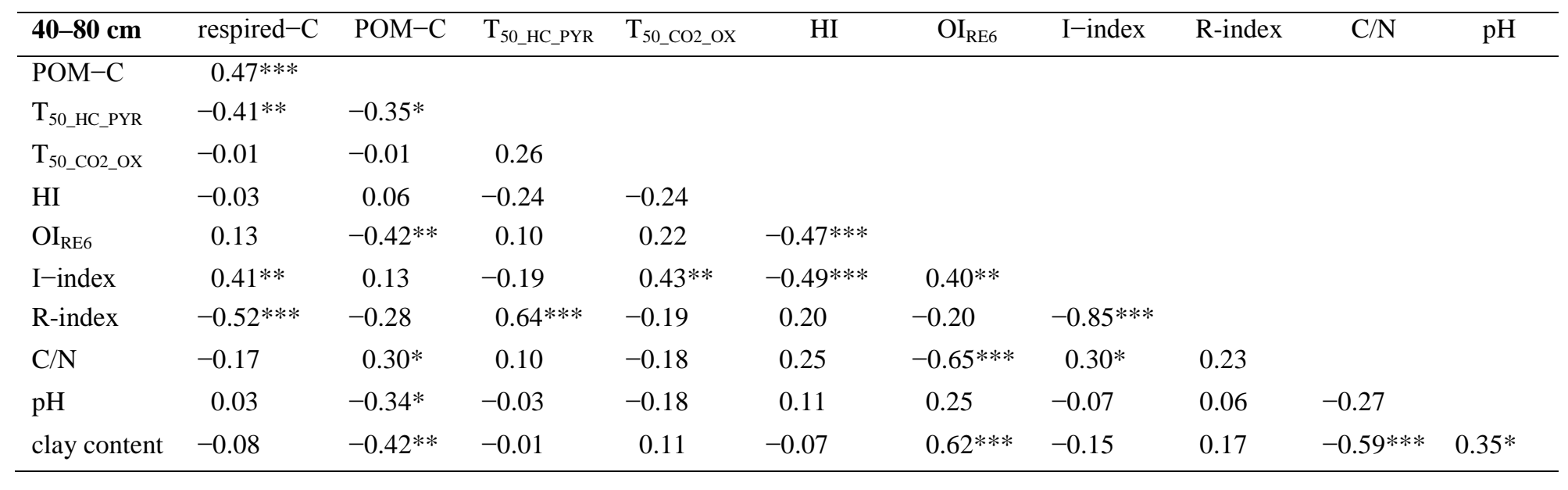




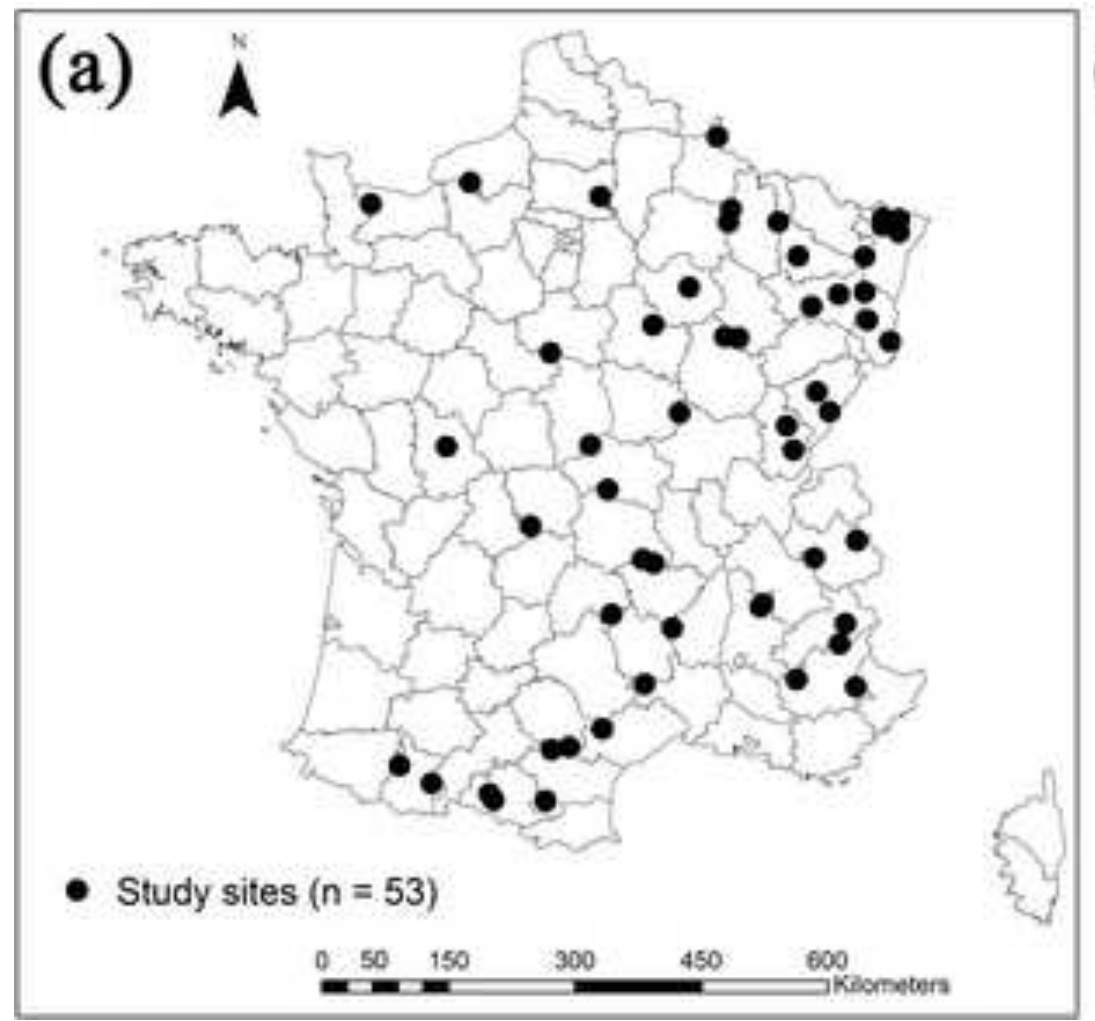

(b) Soil samples from the
RENECOFOR network

Methods used to estimate the size of the labile SOC pool

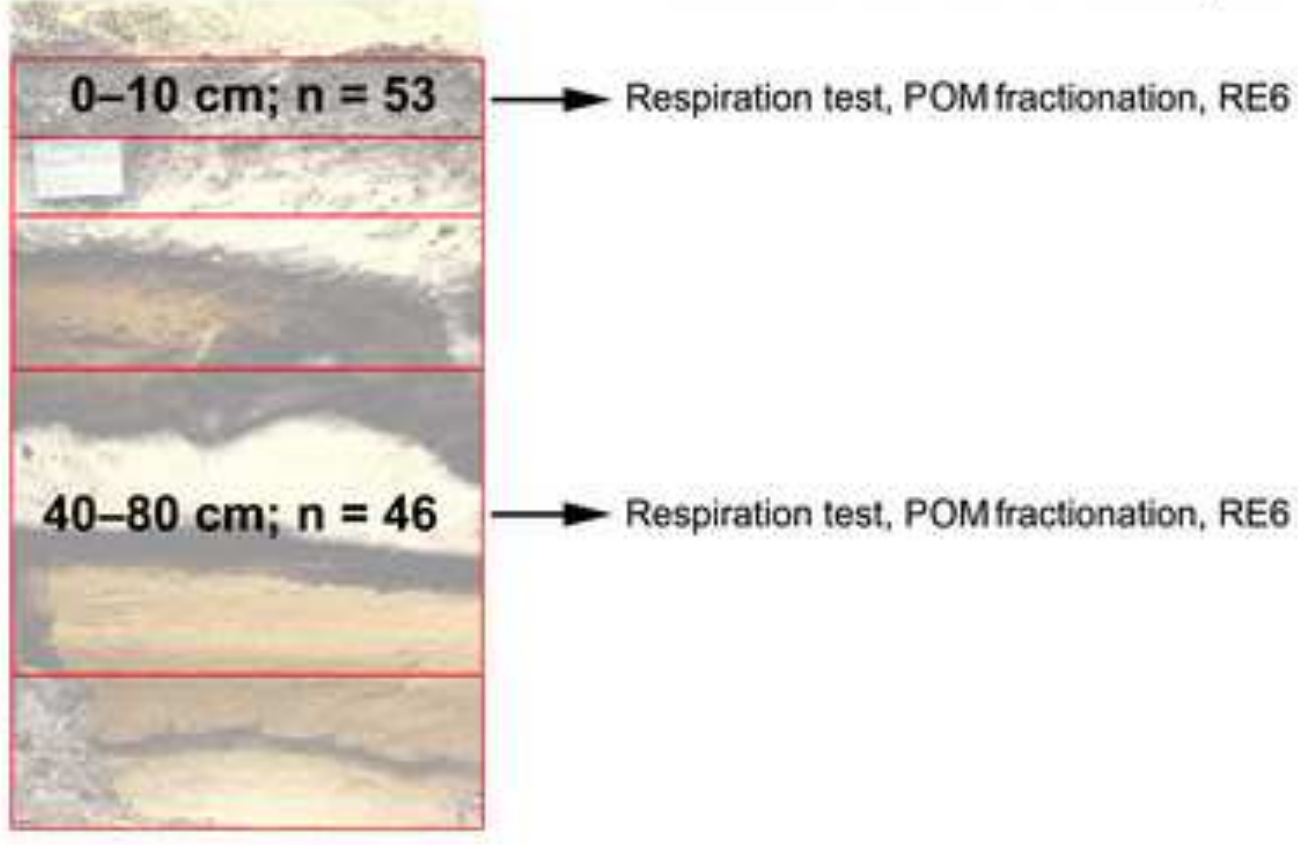


2

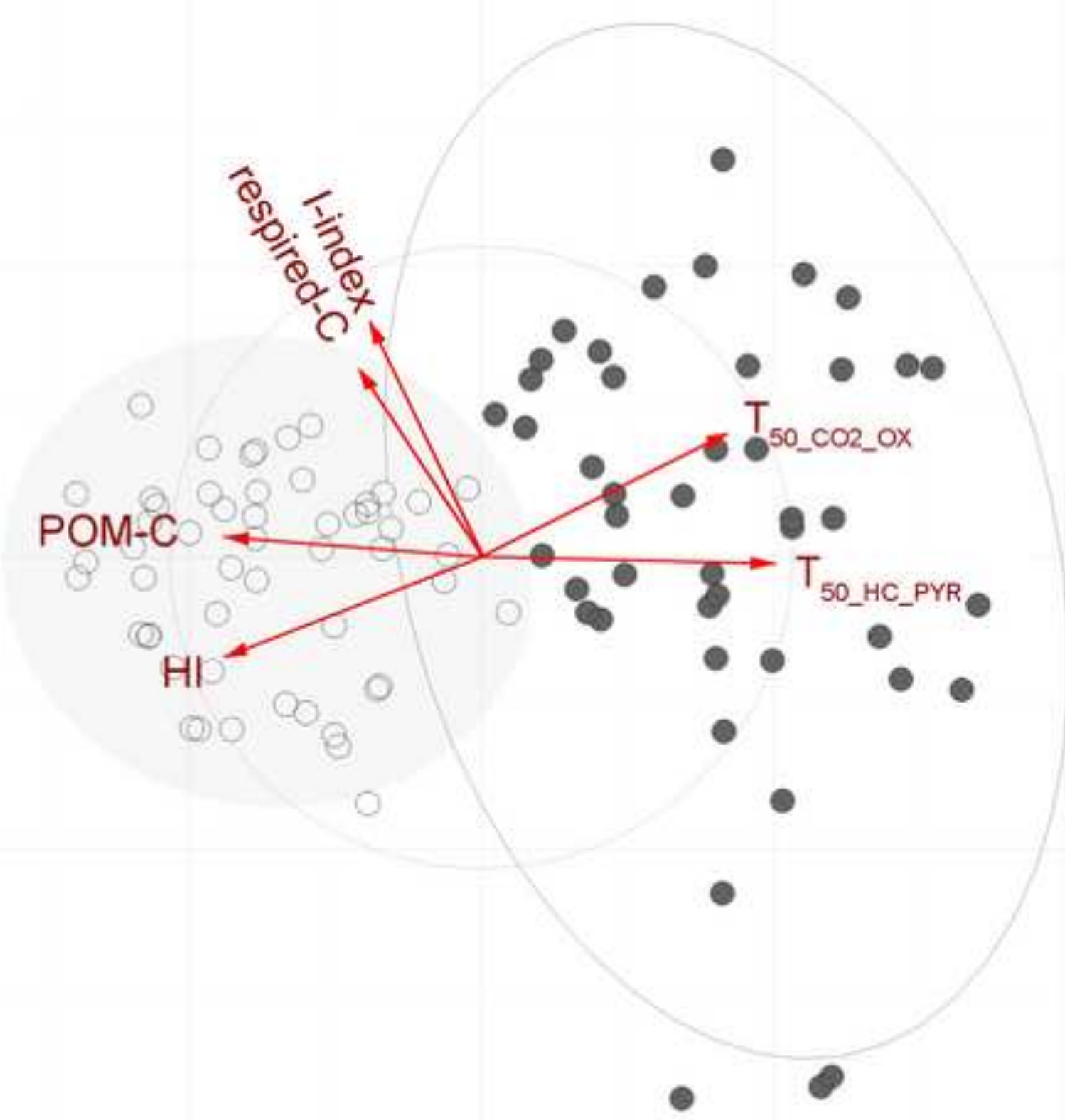

$-4$ 
Click here to download high resolution image

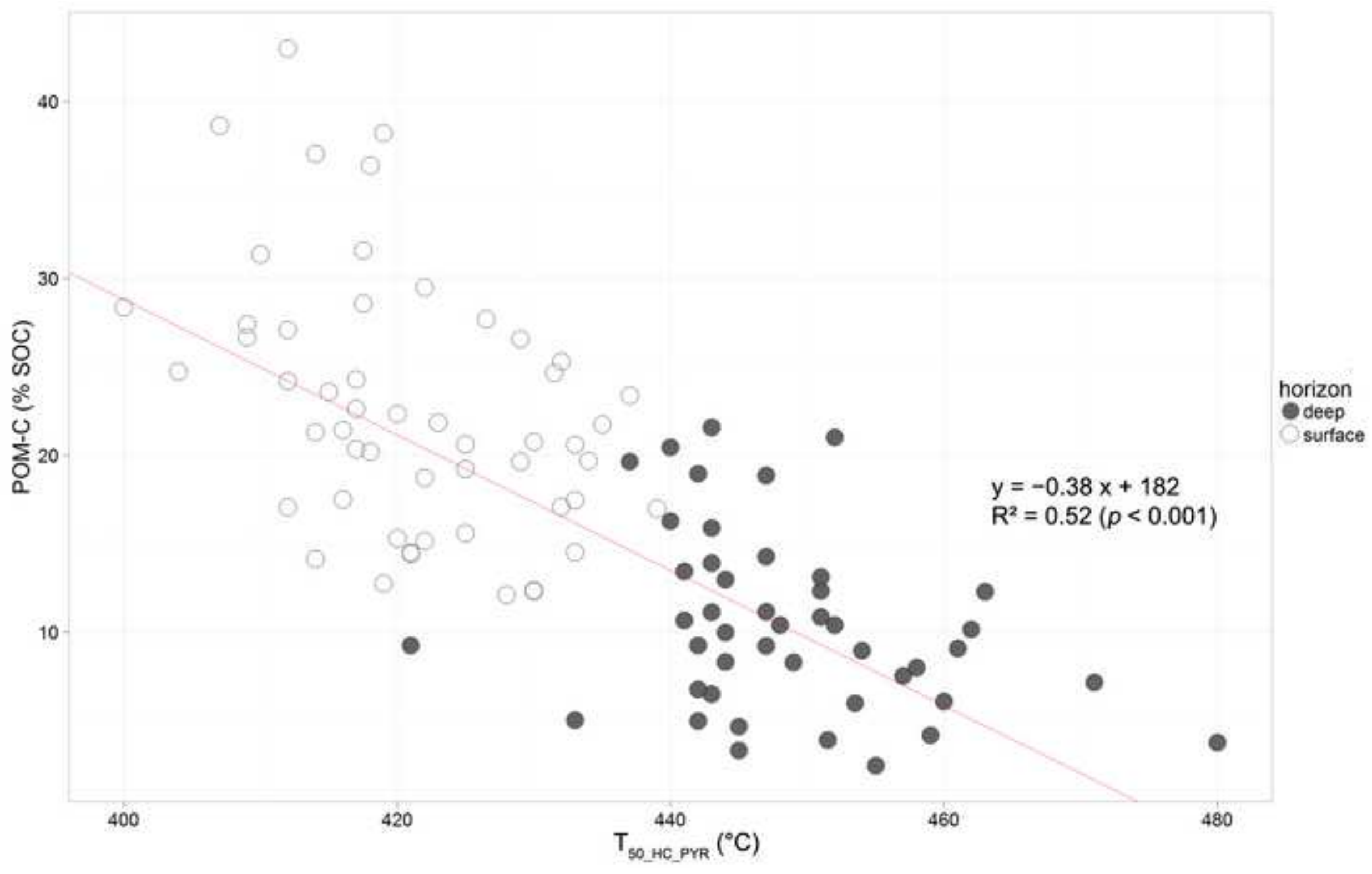


Is Rock-Eval 6 thermal analysis a good indicator of soil organic carbon lability? - A methodcomparison study in forest soils

Laure Soucémarianadin ${ }^{1, *}$, Lauric Cécillon ${ }^{2}$, Claire Chenu ${ }^{3}$, François Baudin ${ }^{4}$, Manuel Nicolas $^{5}$, Cyril Girardin ${ }^{3}$ and Pierre Barré ${ }^{1}$

\section{Supporting Information}

Table SI-A.1. Mean (+ standard deviation) particle-size distribution, $\mathrm{pH}$ and $\mathrm{C} / \mathrm{N}$ ratio of the studied samples.

Table SI-B1. Percentage of variance explained and loadings of the first three principal components (PC) after Box-Cox transformation to correct for skewness for the PCA of all (0$10 \mathrm{~cm}$ and $40-80 \mathrm{~cm})$ samples $(\mathrm{n}=99)$. Values in bold indicate the variables with loading greater than the mean of the absolute loading in each PC.

Table SI-C1. Spearman correlation coefficients between 10-week mineralizable SOC (respired-C), the proportion of OC in the POM fraction (POM-C), the RE6 parameters and the $\mathrm{C} / \mathrm{N}$ ratio of the bulk soil, for the three soil types and the two vegetation types. Significance is indicated as follows: $* * *: \mathrm{p}<0.001 ; * *: \mathrm{p}<0.01 ; *: \mathrm{p}<0.05$. The very high $(>0.9)$ correlations are marked in bold.

Fig. SI-A1. Description of the Rock-Eval 6 thermal analysis (adapted from Saenger et al., 2013) and calculation of four RE6-derived parameters (Hydrogen index; Oxygen index; $\mathrm{T}_{50 \_\mathrm{HC} \_\mathrm{PYR}}$, the temperature at which $50 \%$ of the $\mathrm{HC}$ resulting from the SOM pyrolysis had 
evolved; $\mathrm{T}_{50 \_} \mathrm{CO}_{2} \mathrm{Ox}$, the temperature at which $50 \%$ of the residual $\mathrm{SOM}$ was oxidized to $\mathrm{CO}_{2}$ during the oxidation phase).

Fig. SI-B1. The proportion of OC in the POM fraction (POM-C) as a function of (a) respiredC (the proportion of total SOC mineralizable during a 10-week laboratory incubation); (b) $\mathrm{OI}_{\text {RE6 }}$ (the oxygen index); (c) HI (the hydrogen index); (d) R-index (the proportion of thermally stable SOC pool) for all samples $(\mathrm{n}=99$; surface $=0-10 \mathrm{~cm}$ and deep $=40-80 \mathrm{~cm})$. 


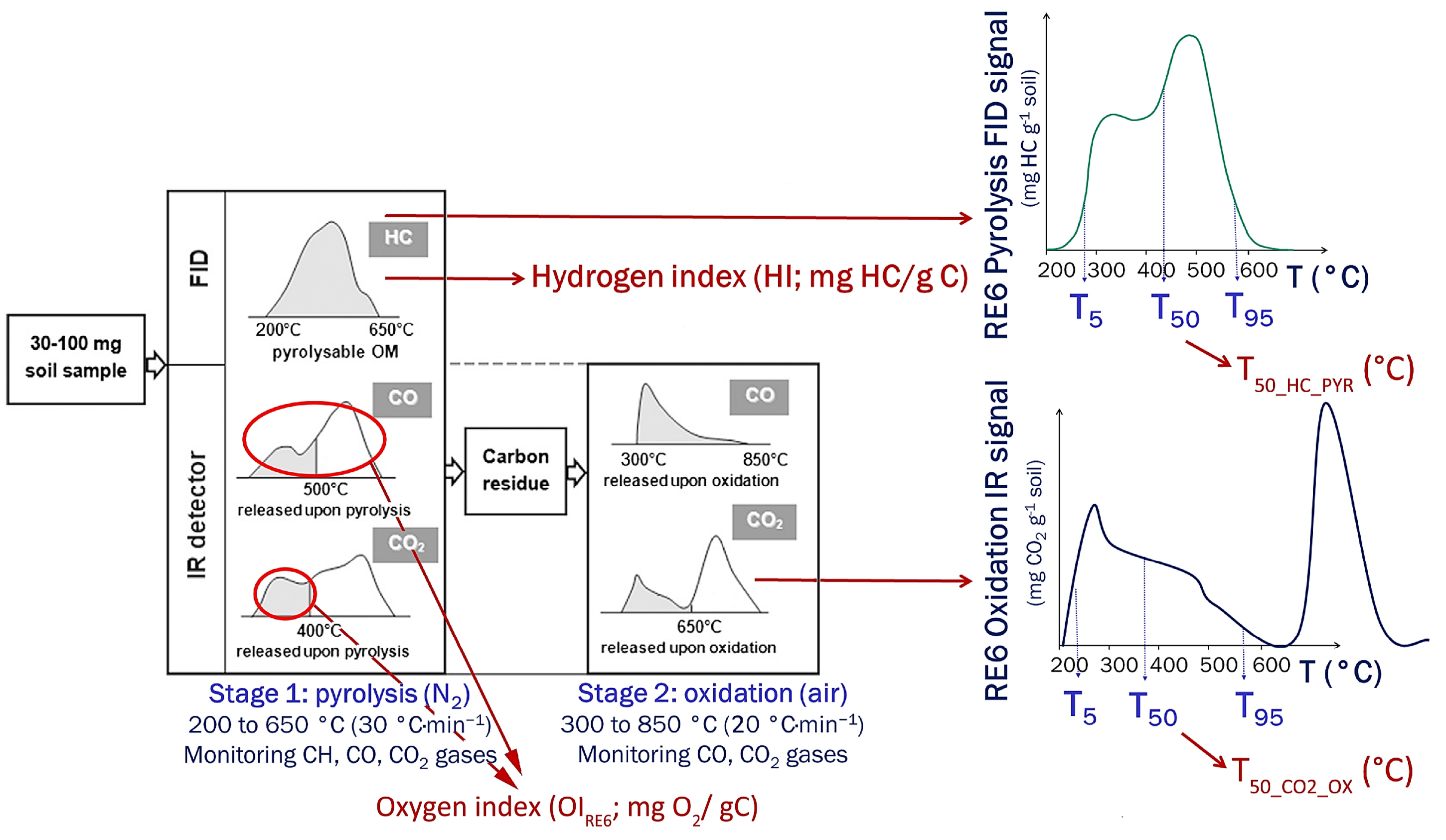


Table SI-A.1. Mean (+ standard deviation) particle-size distribution, $\mathrm{pH}$ and $\mathrm{C} / \mathrm{N}$ ratio of the studied samples in each layer of the 53 plots.

\begin{tabular}{|c|c|c|c|c|c|c|c|c|c|c|}
\hline depth $(\mathrm{cm})$ & $\mathrm{n}$ & clay & $(\%)$ & silt & & sand & $\%)$ & $\mathrm{pH}$ & & $\mathrm{C} / \mathrm{N}$ bulk soil \\
\hline $0-10$ & 53 & 22.5 & $(13.6)$ & 35.5 & $(18.0)$ & 42.0 & $(28.8)$ & 4.9 & $(1.0)$ & 16.9 \\
\hline $40-80$ & 46 & 21.0 & (15.4) & 32.8 & (16.2) & 46.2 & $(26.7)$ & 5.9 & (1.5) & 11.8 \\
\hline
\end{tabular}


Table SI-B1. Percentage of variance explained and loadings of the first three principal components (PC) after Box-Cox transformation to correct for skewness for the PCA of all samples $(\mathrm{n}=99)$. Values in bold indicate the variables with loading greater than the mean of the absolute loading in each PC.

\begin{tabular}{|c|c|c|c|}
\hline $\mathrm{PC}$ & PC1 & $\mathrm{PC} 2$ & $\mathrm{PC} 3$ \\
\hline$\%$ variance explained & 53.2 & 20.1 & 13.1 \\
\hline respired-C & -0.22 & 0.55 & $\mathbf{0 . 7 7}$ \\
\hline POM-C & -0.47 & 0.06 & 0.00 \\
\hline $\mathrm{T}_{50 \_\mathrm{HC} \_\mathrm{PYR}}$ & 0.53 & -0.02 & 0.11 \\
\hline $\mathrm{T}_{50 \_\mathrm{CO} 2 \_\mathrm{OX}}$ & 0.45 & 0.36 & -0.18 \\
\hline HI & -0.46 & -0.29 & -0.15 \\
\hline I-index & -0.20 & 0.69 & -0.58 \\
\hline
\end{tabular}


Table SI-C1. Spearman correlation coefficients between 10-week mineralizable SOC (respired-C), the proportion of OC in the POM fraction (POM-C), the RE6 parameters and the $\mathrm{C} / \mathrm{N}$ ratio of the bulk soil, for the three soil types and the two vegetation types. Significance is indicated as follows: ***: $p<$ $0.001 ; * *: p<0.01 ; *: p<0.05$. The very high $(>0.9)$ correlations are marked in bold.

\begin{tabular}{|c|c|c|c|c|c|c|c|c|c|c|c|}
\hline \multicolumn{12}{|c|}{$\begin{array}{l}\text { SOIL TYPE } \\
\end{array}$} \\
\hline & & respired-C & POM-C & $\mathrm{T}_{50 \text { _HC_PYR }}$ & $\mathrm{T}_{50 \_\mathrm{CO} 2 \_\mathrm{OX}}$ & HI & I-index & $\mathrm{OI}_{\mathrm{RE} 6}$ & R-index & $\mathrm{C} / \mathrm{N}$ & $\mathrm{pH}$ \\
\hline \multirow{10}{*}{ 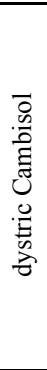 } & POM-C & 0.15 & & & & & & & & & \\
\hline & $\mathrm{T}_{50 \_\mathrm{HC} \_\mathrm{PYR}}$ & $-0.36^{*}$ & $-0.68 * * *$ & & & & & & & & \\
\hline & $\mathrm{T}_{50 \mathrm{CO} 2 \mathrm{OX}}$ & -0.18 & $-0.67 * * *$ & $0.77 * * *$ & & & & & & & \\
\hline & $\mathrm{HI}$ & 0.17 & $0.62 * * *$ & $-0.81 * * *$ & $-0.65^{* * *}$ & & & & & & \\
\hline & I-index & $0.47 * *$ & -0.01 & -0.20 & 0.05 & -0.17 & & & & & \\
\hline & $\mathrm{OI}_{\mathrm{RE} 6}$ & -0.15 & $-0.73 * * *$ & $0.82^{* * *}$ & $0.73^{* * *}$ & $-0.89 * * *$ & 0.15 & & & & \\
\hline & R-index & $-0.50 * *$ & $-0.52 * *$ & $0.90^{* * *}$ & $0.61 * * *$ & $-0.62 * * *$ & $-0.58 * * *$ & $0.63^{* * *}$ & & & \\
\hline & $\mathrm{C} / \mathrm{N}$ & 0.11 & $0.68 * * *$ & $-0.67 * * *$ & $-0.66 * * *$ & $0.58 * * *$ & 0.14 & $-0.75 * * *$ & $-0.64 * * *$ & & \\
\hline & $\mathrm{pH}$ & 0.14 & $-0.60 * * *$ & $0.58 * * *$ & $0.51 * *$ & $-0.61 * * *$ & 0.08 & $0.60 * * *$ & $0.42 *$ & $-0.38^{*}$ & \\
\hline & clay content & -0.30 & -0.16 & 0.15 & -0.02 & -0.03 & $-0.45^{* *}$ & 0.23 & 0.32 & -0.27 & -0.02 \\
\hline \multirow{10}{*}{ 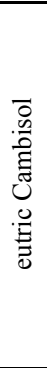 } & POM-C & $0.46^{*}$ & & & & & & & & & \\
\hline & $\mathrm{T}_{50 \_ \text {HC_PYR }}$ & $-0.45^{*}$ & $-0.68 * * *$ & & & & & & & & \\
\hline & $\mathrm{T}_{50 \_\mathrm{CO} 2 \_\mathrm{OX}}$ & $-0.54 * *$ & $-0.53 * *$ & $0.77^{* * *}$ & & & & & & & \\
\hline & $\mathrm{HI}$ & 0.31 & $0.72^{* * *}$ & $-0.52 * *$ & $-0.48 * *$ & & & & & & \\
\hline & I-index & $0.39 *$ & $0.37^{*}$ & $-0.58 * * *$ & -0.36 & 0.21 & & & & & \\
\hline & $\mathrm{OI}_{\mathrm{RE} 6}$ & $-0.42 *$ & $-0.88^{* * *}$ & $0.68 * * *$ & $0.55^{* *}$ & $-0.83 * * *$ & $-0.39^{*}$ & & & & \\
\hline & R-index & $-0.50 * *$ & $-0.68 * * *$ & $0.94 * * *$ & $0.72 * * *$ & $-0.55^{* *}$ & $-0.78 * * *$ & $0.70^{* * *}$ & & & \\
\hline & $\mathrm{C} / \mathrm{N}$ & $0.41 *$ & $0.84 * * *$ & $-0.60 * * *$ & $-0.49 * *$ & $0.71 * * *$ & 0.17 & $-0.82 * * *$ & $-0.54 * *$ & & \\
\hline & $\mathrm{pH}$ & $-0.57 * * *$ & $-0.56 * *$ & $0.69^{* * *}$ & $0.71^{* * *}$ & $-0.54 * *$ & -0.20 & $0.62 * * *$ & $0.62 * * *$ & $-0.56^{* *}$ & \\
\hline & clay content & -0.03 & -0.13 & -0.08 & -0.08 & -0.03 & -0.14 & -0.05 & 0.01 & 0.01 & -0.25 \\
\hline \multirow{10}{*}{ 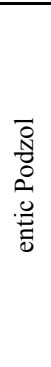 } & POM-C & $0.42^{*}$ & & & & & & & & & \\
\hline & $\mathrm{T}_{50 \_ \text {HC_PYR }}$ & $-0.35^{*}$ & $-0.86^{* * *}$ & & & & & & & & \\
\hline & $\mathrm{T}_{50 \_\mathrm{CO} 2 \_\mathrm{OX}}$ & -0.24 & $-0.52 * *$ & $0.69^{* * *}$ & & & & & & & \\
\hline & $\mathrm{HI}$ & 0.18 & $0.71 * * *$ & $-0.75 * * *$ & $-0.57 * * *$ & & & & & & \\
\hline & I-index & 0.31 & $0.55^{* * *}$ & $-0.69 * * *$ & -0.30 & 0.27 & & & & & \\
\hline & $\mathrm{OI}_{\mathrm{RE} 6}$ & -0.15 & $-0.71 * * *$ & $0.75 * * *$ & $0.48^{* *}$ & $-0.96 * * *$ & -0.26 & & & & \\
\hline & R-index & -0.32 & $-0.83 * * *$ & $0.97^{* * *}$ & $0.62 * * *$ & $-0.68 * * *$ & $-0.81 * * *$ & $0.68 * * *$ & & & \\
\hline & $\mathrm{C} / \mathrm{N}$ & 0.08 & $0.54 * *$ & $-0.55 * * *$ & $-0.44 *$ & $0.74 * * *$ & 0.13 & $-0.70 * * *$ & $-0.46 * *$ & & \\
\hline & $\mathrm{pH}$ & -0.29 & $-0.69 * * *$ & $0.83^{* * *}$ & $0.72^{* * *}$ & $-0.71 * * *$ & $-0.48^{* *}$ & $0.72 * * *$ & $0.79^{* * *}$ & $-0.55^{* * *}$ & \\
\hline & clay content & -0.01 & -0.10 & -0.06 & -0.29 & -0.15 & 0.05 & 0.23 & -0.06 & $-0.39 *$ & 0.02 \\
\hline
\end{tabular}


VEGETATION TYPE

\begin{tabular}{|c|c|c|c|c|c|c|c|c|c|c|}
\hline & respired-C & POM-C & $\mathrm{T}_{50 \_ \text {HC_PYR }}$ & $\mathrm{T}_{50 \_\mathrm{CO} 2 \text { OXX }}$ & $\mathrm{HI}$ & I-index & $\mathrm{OI}_{\mathrm{RE} 6}$ & R-index & $\mathrm{C} / \mathrm{N}$ & $\mathrm{pH}$ \\
\hline POM-C & 0.20 & & & & & & & & & \\
\hline $\mathrm{T}_{50 \_ \text {HC_PYR }}$ & -0.25 & $-0.67 * * *$ & & & & & & & & \\
\hline $\mathrm{T}_{50 \_\mathrm{CO} 2 \_\mathrm{OX}}$ & -0.24 & $-0.52 * * *$ & $0.72 * * *$ & & & & & & & \\
\hline HI & 0.05 & $0.70^{* * *}$ & $-0.82 * * *$ & $-0.67 * * *$ & & & & & & \\
\hline I-index & $0.29^{*}$ & $0.38^{* *}$ & $-0.52 * * *$ & -0.16 & 0.21 & & & & & \\
\hline $\mathrm{OI}_{\mathrm{RE} 6}$ & 0.00 & $-0.75 * * *$ & $0.76^{* * *}$ & $0.58^{* * *}$ & $-0.92 * * *$ & -0.27 & & & & \\
\hline R-index & -0.25 & $-0.68 * * *$ & $0.95 * * *$ & $0.63 * * *$ & $-0.75 * * *$ & $-0.74 * * *$ & $0.74 * * *$ & & & \\
\hline $\mathrm{C} / \mathrm{N}$ & -0.13 & $0.60^{* * *}$ & $-0.46^{* * *}$ & $-0.33^{*}$ & $0.73 * * *$ & 0.19 & $-0.80^{* * *}$ & $-0.47^{* * *}$ & & \\
\hline $\mathrm{pH}$ & $0.37 * *$ & $-0.54 * * *$ & $0.42 * *$ & $0.37 * *$ & $-0.64 * * *$ & -0.18 & $0.70^{* * *}$ & $0.45^{* * *}$ & $-0.66^{* * *}$ & \\
\hline clay content & $0.27^{*}$ & -0.20 & -0.11 & $-0.32 *$ & -0.15 & -0.09 & $0.33^{*}$ & -0.01 & $-0.51 * * *$ & 0.50 *** \\
\hline POM-C & 0.21 & & & & & & & & & \\
\hline $\mathrm{T}_{50 \_\mathrm{HC} \text { _PYR }}$ & -0.29 & $-0.80^{* * *}$ & & & & & & & & \\
\hline $\mathrm{T}_{50 \_\mathrm{CO} 2 \text { OXX }}$ & -0.07 & $-0.56 * * *$ & $0.70^{* * *}$ & & & & & & & \\
\hline $\mathrm{HI}$ & 0.10 & $0.69^{* * *}$ & $-0.83 * * *$ & $-0.73 * * *$ & & & & & & \\
\hline I-index & $0.40^{* *}$ & 0.17 & -0.24 & 0.15 & -0.04 & & & & & \\
\hline $\mathrm{OI}_{\mathrm{RE} 6}$ & -0.05 & $-0.77 * * *$ & $0.84 * * *$ & $0.69 * * *$ & $-0.92 * * *$ & 0.03 & & & & \\
\hline R-index & $-0.44 * *$ & $-0.73 * * *$ & $0.92^{* * *}$ & $0.52 * * *$ & $-0.66^{* * *}$ & $-0.57^{* * *}$ & $0.67^{* * *}$ & & & \\
\hline $\mathrm{C} / \mathrm{N}$ & -0.16 & $0.67^{* * *}$ & $-0.66^{* * *}$ & $-0.66^{* * *}$ & $0.81 * * *$ & -0.20 & $-0.86 * * *$ & $-0.46^{* *}$ & & \\
\hline pH & 0.07 & $-0.55 * * *$ & $0.52 * * *$ & $0.42 * *$ & $-0.53 * * *$ & -0.19 & $0.60^{* * *}$ & $0.52 * * *$ & $-0.61 * * *$ & \\
\hline clay content & 0.09 & -0.12 & 0.16 & 0.15 & -0.26 & -0.25 & 0.27 & 0.24 & $-0.34 *$ & $0.35^{*}$ \\
\hline
\end{tabular}

